Portland State University

PDXScholar

\title{
Modeling of Ultrafine Particle Emissions and Ambient Levels for the Near Roadside Environment
}

Sauda Ahmed

Portland State University

Follow this and additional works at: https://pdxscholar.library.pdx.edu/open_access_etds

Part of the Environmental Sciences Commons

Let us know how access to this document benefits you.

\section{Recommended Citation}

Ahmed, Sauda, "Modeling of Ultrafine Particle Emissions and Ambient Levels for the Near Roadside Environment" (2017). Dissertations and Theses. Paper 3506.

https://doi.org/10.15760/etd.5390

This Thesis is brought to you for free and open access. It has been accepted for inclusion in Dissertations and Theses by an authorized administrator of PDXScholar. Please contact us if we can make this document more accessible: pdxscholar@pdx.edu. 
Modeling of Ultrafine Particle Emissions and Ambient Levels for the

Near Roadside Environment

by

Sauda Ahmed

A thesis submitted in partial fulfillment of the requirements for the degree of

Master of Science

in

Environmental Science and Management

Thesis Committee:

Linda A. George, Chair

Dean Atkinson

John Rueter

Portland State University

2017 


\begin{abstract}
Various epidemiological studies have linked exposure to Ultrafine Particles (UFP; diameter $<100 \mathrm{~nm}$ ) to adverse health impacts. Roadway traffic is one of the major sources of UFPs and heavily influences UFP concentrations in the nearby vicinity of major roadways. Modeling efforts to predict UFPs have been limited due to the scarcity of reliable information on emissions, lack of monitoring data and limited understanding of complex processes affecting UFP concentrations near sources.
\end{abstract}

In this study continuous measurement of ultrafine particle number concentrations (PNC) and mass concentrations of nitric oxide (NO), nitrogen dioxide $\left(\mathrm{NO}_{2}\right)$ and $\mathrm{PM}_{2.5}$ was conducted near an arterial road and freeway at different seasons and meteorological conditions and integrated with traffic count data. PNC showed high correlation with NO ( $r=0.64$ for arterial; 0.61 for freeway), $\mathrm{NO}_{2}$ ( $r=0.57$ for arterial; 0.53 for freeway) and NOx (NOx=NO+NO2; r=0.63 for arterial; 0.59 for freeway) and moderate to low correlation with traffic volume ( $r=0.33$ for arterial; 0.32 for freeway) and $\mathrm{PM}_{2.5}$ ( $\mathrm{r}=0.28$ for arterial; 0.23 for freeway); respectively; for both sites at 15 minute averages. The $\mathrm{PNC}-\mathrm{NO}_{\mathrm{x}}$ relationship prevailed on a shorter term (15 min), hourly, and throughout the day basis. Both PNC and NOx showed comparatively higher correlation with traffic during the morning period but became lower during evening which can be attributed to the higher boundary layer and wind speeds. The variable meteorology in the evening affects both PNC and NOx concentrations in the same way and the 
correlation between NOx and PNC is maintained high both during morning $(r=0.74$ for arterial; 0.69 for freeway), and evening ( $r=0.62$ for arterial; 0.59 for freeway) periods. Thus nitrogen oxides can be used as a proxy for traffic-related UFP number concentration reflecting the effect of both traffic intensity and meteorological dilution.

The PNC-NOx relation was explored for various meteorological parameters i.e. wind speed and temperature. It is found that NOx emission is temperature independent and can be used to reflect the effect of traffic intensity and meteorological dilution. Once the effect of traffic intensity and dilution is removed, the effect of temperature on PNC-NOx ratio becomes important which can be attributed to the variation in PNC emission factors with temperature.

The high morning PNC-NOx ratio found at the arterial road is a result of new particle formation due to lower temperature and low concentration of exhaust gases in the morning air favoring nucleation over condensation. This finding has important implication when calculating emission factors for UFP number concentrations. Thus it can be concluded that roadside concentration of ultrafine particles not only depends on traffic intensity but also on meteorological parameters affecting dilution or new particle formation. High concentrations of ultrafine particle number concentration close to a roadway is expected due to higher traffic intensity, as well as during low wind speed causing low dilution and low temperature conditions favoring new particle formation.

Finally a simplified approach of calculating particle number emission factor was developed using existing and easily available emission inventory for traffic related tracer 
gases. Using NOx emission factors from MOVES emission model, the emission ratio of PNC to NOx was converted to develop particle number emission factors. NOx was selected as the traffic related tracer gas since the number concentration of particles is closely correlated to NOx, NOx and particles are diluted in the same way and NOx emission factors are available for a variety of traffic situations. To ensure contribution of fresh traffic exhaust, the average of the difference of pollutant concentrations at high

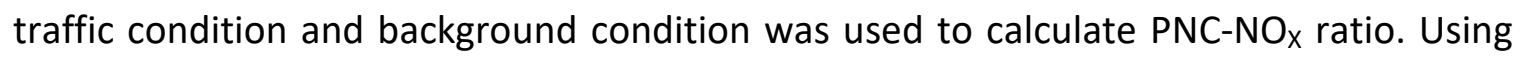
nitrogen oxides to define background and high-traffic conditions and MOVES emission

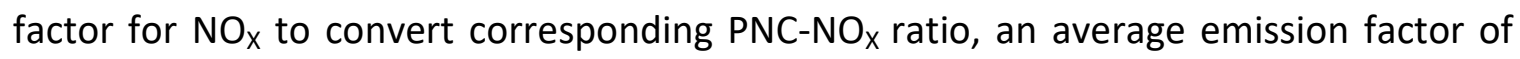
$(1.82 \pm 0.17) \mathrm{E}+14$ particle/ vehicle-km was obtained, suitable for summertime. When compared to existing particle number emission factors derived from dynamometer tests, it was found that there exits reasonable agreement between the calculated real world particle number emission factors and emission factors from dynamometer tests.

The calculated emission factor and R-Line dispersion model was tested in predicting near-road particle number concentrations. Although only $23 \%$ of the variability in PNC was explained by the dispersion model, $84.33 \%$ of the measurements fell within the factor of two envelope. This suggests that there is potential to effectively use these models and thus warrants more in-depth analysis. Finally, a simple map of PNC gradients from major roads of Portland was developed.

The results of this study helped identify proxy-indicators to provide reference values for estimating UFP concentrations and emissions that can be used for simple 
evaluation of particle concentration near major roadways for environmental and urban planning purposes and to assess expected impact of UFP pollution on population living near roadways exposed to elevated concentrations. 


\section{Acknowledgements}

First of all, I would like to thank my advisor, Dr. Linda A. George for her constant supervision and guidance throughout my graduate and research journey. Without her support, I could not have started my journey as an International graduate student at Portland state University. I also thank my committee members, Dr. Dean Atkinson and Dr. John Rueter, for their time, insightful feedback on my thesis and cooperation in every sphere of my academic life. I would also like to thank Anthony Barnack and Kathleen Schuckman from Oregon Department of Environmental Quality, for giving me access to data and permission to set up instrumentation in their air quality station.

Thanks to all my lab-mates for their continuous support. Thanks to Dr. Christine M. Kendrick for training me on near road air quality measurements and providing access to data. I would also like to acknowledge the talented staff and faculty in the Department of Environmental Science and Management at PSU. I am grateful to the Department for providing vital financial support through a Teaching Assistantship.

Finally, I would like to thank my parents, Irene Chowdhury and A. K. M. Saleh Ahmed, who are the reason for everything good in my life and also my husband, Mohammed Imrul Hossain, for his endless encouragement and support. 


\section{Table of Contents}

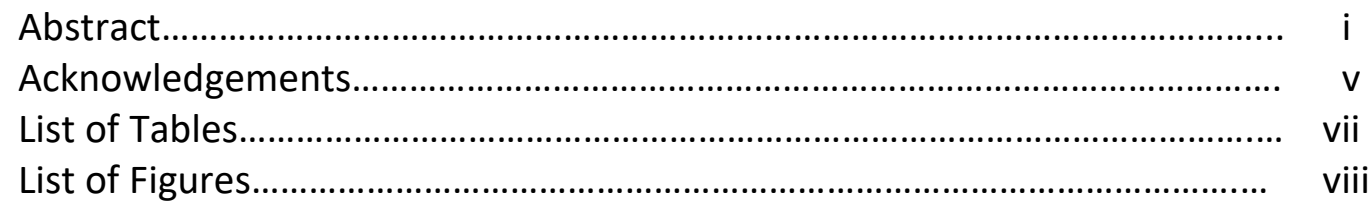

Chapter 1 Introduction ............................................................................................. 1

1.1 Characterization of Ultrafine Particles........................................................ 3

1.2 Sources of Ultrafine particles in urban environment.................................. 8

1.3 Ultrafine Particles in near roadway environment...................................... 10

1.3.1. Emissions of ultrafine particles from vehicles...................................... 11

1.3.2. Environmental fate and transport of vehicle generated UFPs......... 14

1.3.3 Factors affecting ear roadway exposure.............................................. 18

1.4 Health Impacts of ultrafine particles........................................................ 20

Chapter 2 Characterizing Roadside Ultrafine Particle Number Concentration and Correlation with traffic related pollutants.................................................................... 24

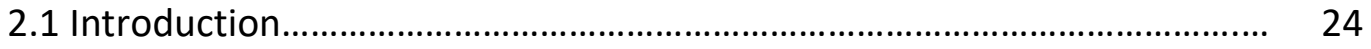

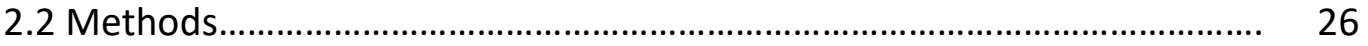

2.2.1 Site description and measurements.................................................... 26

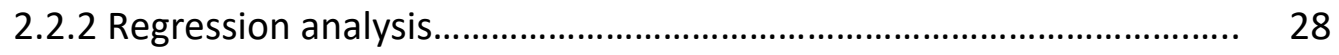

2.3 Results.............................................................................................. 29

2.3.1 Relationship of Ultrafine particle number concentrations with traffic volume and co-pollutants....................................................... 29

2.3.2 Diurnal variation of PNC and NOX with traffic volume....................... $\quad 34$

2.3.3 Effect of ambient temperature and wind speed on PNC-NOx ratio............. 38

2.4 Conclusion ............................................................................................ 45

Chapter 3 Determination and application of average emission factors for ultrafine $\quad 48$ particle number concentration.

3.1 Introduction ......................................................................................... 48

3.2 Theory and Methodology...................................................................... 50

3.2.1 Calculation of emission ratio................................................................ 53

3.2.2 R-LINE Dispersion Model..................................................................... $\quad 55$

3.2.3 Site Description and measurements................................................. 57

3.3 Results......................................................................................... 58

3.4 Conclusion.......................................................................................... 69

Chapter 4 Implications and Future Directions...………………………………….... 72

References................................................................................................... 75 


\section{List of Tables}

Table1.1 Particle number and particle surface area per given mass of ambient particles...................................................................................................... 5

Table 1.2 Effect of various atmospheric processes on UFP number and

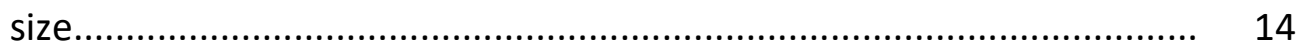

Table 2.1 Summary of roadside pollutant concentrations at 15 minute averages.......................................................................................... 30

Table 2.2 Correlation ( $p<0.001$ ) of Ultrafine PNC with traffic volume and copollutants. (a) Arterial road; (b) Freeway

Table 2.3 Table 2.3 Correlation $(p<0.001)$ of pollutants with traffic volume at different times of the day, (a) Arterial road; (b) Freeway

Table 3.1 Average concentrations of pollutants at high-traffic (defined by high NO to NO2 ratio) and background conditions (defined by low NOx concentrations).

Table 3.2 On road emission ratios from studies conducted in urban roadside settings.

Table 3.3 Summary of Particle Number emission factors calculated using NOx emission factor

Table 3.4 Particle Number emission factor from dynamometer tests.................................................................................................. 63

Table 3.5 Average concentrations for High- traffic and background conditions defined by $\mathrm{CO}$ concentrations

Table 3.6 Emission ratios calculated using either NOx or CO to identify Hightraffic and background conditions 


\section{List of Figures}

Figure 1.1 Relative size of UFP relative to human hair and other particle sizes......

Figure 1.2 Particle number and size distribution in ambient air.............................. 6

Figure 1.3 Mean and median values of UFP number concentration at different outdoor environment........................................................................... 7

Figure 1.4 Major Combustion Sources of Ultrafine Particles.................................... 9

Figure 1.5 Particle mass and number concentrations from various engine technologies......

Figure 1.6 Illustration of Nucleation, condensation and Coagulation processes.

Figure 1.7 The range of UFP concentrations reported in the literature for various spatial scale

Figure 1.8 The variation of UFP number concentration while walking along high and low traffic roads in Toronto, Canada.

Figure 1.9 Predictions of the ICRP (1994) model in terms of the fractional deposition in each region as a function of the size of the inhaled particles.

Figure 1.10 Particle number deposition fraction at rest and exercise in healthy and asthmatic subjects

Figure 2.1 Diurnal Variation of UFP and NOx for Arterial ( $a$ and b) and Freeway (c and d)

Figure 2.2 Diurnal Variation of PNC-NOx ratio (a) Arterial road; (b)

Freeway.

Figure 2.3 Scatter plot of PNC and NOx concentrations against wind speed;

Arterial road $(a, b)$; Freeway $(c, d)$

Figure 2.4 Scatter plot of PNC - NOx ratio against wind speed; (a) Arterial road;

(b) Freeway

Figure 2.5 Scatter plot of PNC and NOx concentrations against ambient temperature; Arterial road (a,b); Freeway (c,d).

Figure 2.6 Scatter plot of PNC - NOx ratio against ambient temperature; (a)

Arterial road; (b) Freeway.

Figure 2.7 Diurnal $\mathrm{PM}_{2.5}$ at the arterial road.

Figure 2.8 Relationship between hourly averages of PNC and NOx concentrations at different ambient air temperatures

Figure 3.1 (a) Average hourly speed of traffic on I -5 collected from PORTAL; (b) Speed based MOVES emission factor for NOX ; (c) Speed based MOVES emission factor for $C O$ 
Figure 3.2 Average PNC emission factor derived using NOx emission factors.........

$\begin{array}{lll} & & 61 \\ \text { Figure 3.3 } & \text { Modeled vs. Measured particle number concentrations ......................... } & 67\end{array}$

Figure 3.4 Average summertime hourly concentrations of PNC from traffic sources for Portland, OR......................................................................... 
CHAPTER 1: Introduction

Emission from traffic is a major source of local variability in air pollution levels, with the highest concentrations and risk of exposure occurring near roads. Almost 59.5 million people in United states live within $500 \mathrm{~m}$ of roads with annual average daily traffic (AADT) of greater than 25000 vehicle/ day (Rowangould et al., 2013) [1] and exposed to complex mixture of criteria air pollutants emitted from motor vehicles including carbon monoxide (CO), nitrogen oxides (NOx), various hydrocarbons and fine particulate matters.

Particulate matter (PM) has long been noted as an important atmospheric pollutant and has been linked to numerous adverse health outcomes and remains a major environmental challenge (Pope and Dockery, 2006) [2]. Generally, the larger diameter particles have been the pollutant of concern. Conventionally, PM mass concentrations have been used as an indicator of exposure to PM in various epidemiological studies without taking into account of the number concentration or size distribution. Also the existing PM regulations in the U.S. are mass-based standards because it can be measured relatively simply and accurately on a continuous basis. However, atmospheric particles originate from a variety of sources and generally produce a broad range of particles, both in terms of size and chemical composition. Thus, mass concentration is a relatively broad indicator for the particle mixture contained in ambient air. Particle size is an important defining property of ambient PM since size governs the transport and removal of particles from the air and the biological 
interaction in the human respiratory system and is at least partly associated with the chemical composition and sources of particles (WHO, 2004)[3].

With the advancement of science and technology of air quality measurements, we are now able to measure concentrations of particles at more refined levels of detection and can assess more comprehensively the potential human health concerns related to particles. In recent years, there has been increasing evidence that smaller particles are of significant human health concern since they have a higher probability of penetrating into and depositing in lower parts of the human lung and entering the bloodstream than larger particles, which are removed more efficiently by the defense mechanism of the mucociliary system (Daigle et al. 2003)[4].

This fraction of particulate matter in the ambient air are defined as Ultrafine Particles (UFP) and characterized as particles with an aerodynamic diameter of 100 nanometers $(\mathrm{nm})$ or 0.1 micrometers $(\mu \mathrm{m})$ or less. Ultrafine particle research is an emerging topic and is a relatively new field of investigation. UFPs were overlooked as a significant factor in respiratory tract health and hence an important consideration in air quality assessments for a long time until Oberdorster and Utell, (2002)[5], introduced the hypothesis that UFP could cause toxicity to the human respiratory tract. In addition to the size of UFPs, number concentration plays an important role in assessing the health impact because they constitute the largest contributor to overall particle numbers emitted from engine combustion. The greatest number of particles and the greatest amount of lung deposition occurs in the ultrafine particle size range. Since UFP 
are very small in size and volume, the aggregate mass of ultrafine particles is not significant compared to larger particles but they are high in terms of number concentrations. The occurrence of these elevated levels of UFP number concentrations is mostly observed in urban areas and near emission sources. Therefore exposure to UFP near busy highways and other major roads is a topic that deserves additional research and attention.

Despite a significant body of suggestive evidence linking ultrafine particles to adverse health effects, there are currently no legal ambient standards. At present, there lacks a large scale monitoring network for measuring number concentration of PM in the United States and thereby exists a gap in our knowledge of the understanding of UFPs and exposure assessment. The work presented here uses long-term roadside measurement of particle number concentration and meteorological parameters collected at an major arterial road and freeway in Portland, OR, in an effort to better understand the behavior of ultrafine particles in the near field and the various atmospheric processes affecting the relationship between UFP and various co pollutants.

\subsection{Characterization of Ultrafine Particles}

Size, shape, physical properties and chemical composition are important properties that are used to characterize ambient PM. Size are the most defining property of ultrafine 
particles. UFPs are defined as particles with an aerodynamic diameter of 100 nanometers $(\mathrm{nm})$ or 0.1 micrometers $(\mu \mathrm{m})$ or less. They are a sub-fraction of the currently regulated PM2.5 (particles with a diameter less than $2.5 \mu \mathrm{m}$ ) and PM10 (particles with a diameter less than $10 \mu \mathrm{m}$ ). So UFPs have diameter that is 25 times smaller than PM2.5 and 100 times smaller than PM10.

Figure 1.1 illustrates the relative size of UFP relative to human hair and other particle sizes. PM2.5 and PM10 diameter is almost 24 and 6 times smaller, respectively, than human hair which typically has a diameter of $60 \mu \mathrm{m}$. For UFP, the diameter is 600 times smaller than human hair.

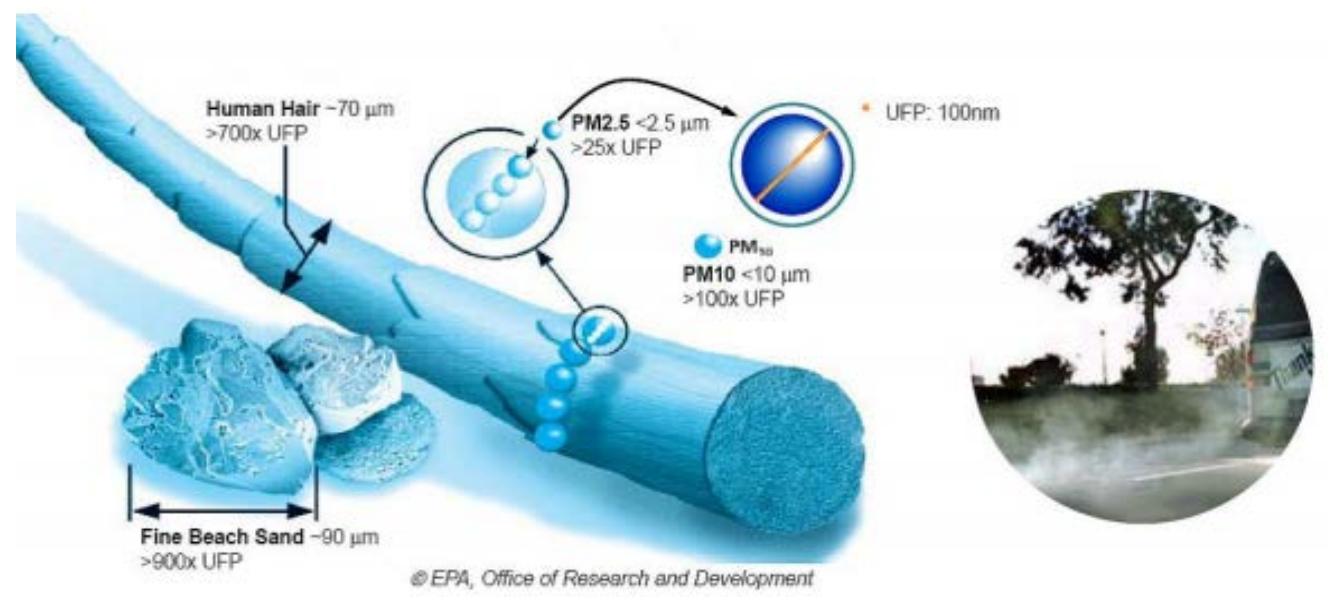

Figure 1.1 Relative size of UFP relative to human hair and other particle sizes (Source: EPA office of Research and Development)

Since UFP are very small in size and volume, the aggregate mass of ultrafine particles is not significant compared to larger particles but they constitute the largest contributor to overall particle numbers. So the number of UFPs in a given mass will be thousands to tens-of-thousands more than the number of larger particle in an 
equivalent mass. The ultrafines 'escape' existing PM standards because they contribute very little to the total mass of particulate matter in air. In the measurements the presence of these very fine particles is easily obscured by only a few larger particles. Table 1.1 shows that for a given mass concentration of particles, the number of particles per unit volume of air increase dramatically along with the surface area as the particle size decreases.

Table 1.1 Particle number and particle surface area per given mass of ambient particles

\begin{tabular}{|c|c|c|c|}
\hline Particle Mass & Particle diameter & Number & Particle surface area \\
\hline $\begin{array}{c}\text { Concentration } \\
\left(\mu \mathrm{g} / \mathrm{m}^{3}\right)\end{array}$ & $(\mu \mathrm{m})$ & $\begin{array}{c}\text { Concentration } \\
\text { (Particle } / \mathrm{cm}^{3} \text { of air) }\end{array}$ & $\left(\mu \mathrm{m}^{2} / \mathrm{cm}^{3}\right.$ air $)$ \\
\hline 10 & 2 & 1.2 & 24 \\
\hline 10 & 0.5 & 153 & 120 \\
\hline 10 & 0.02 & 2400000 & 3016 \\
\hline
\end{tabular}

Source: (Oberdorster $\mathrm{G}$ et al., 2005)[6]

The UFP fraction dominates the urban aerosol numbers up to $80 \%$ (Morawska et al., 1998)[7]. Stainer et al. (2004)[8] showed $75 \%$ of the number of ambient PMs are below $50 \mathrm{~nm}$ in diameter. This higher number concentration corresponds to higher surface area and thus indicates increased toxicity.

Thus, UFPs dominate the number concentration of ambient PM while less numerous but much heavier particles (i.e. PM2.5 and PM10) dominate mass concentration measurements. Figure 1.2 shows that in ambient air, the smallest particles are generally more numerous, and the number distribution of particles generally peaks below $0.1 \mathrm{~m}$. The size range below $0.1 \mathrm{~m}$ is referred to as the ultrafine 
range. The largest particles $(0.1-10 \mathrm{~m})$ are small in number but contain most of the PM volume (mass).

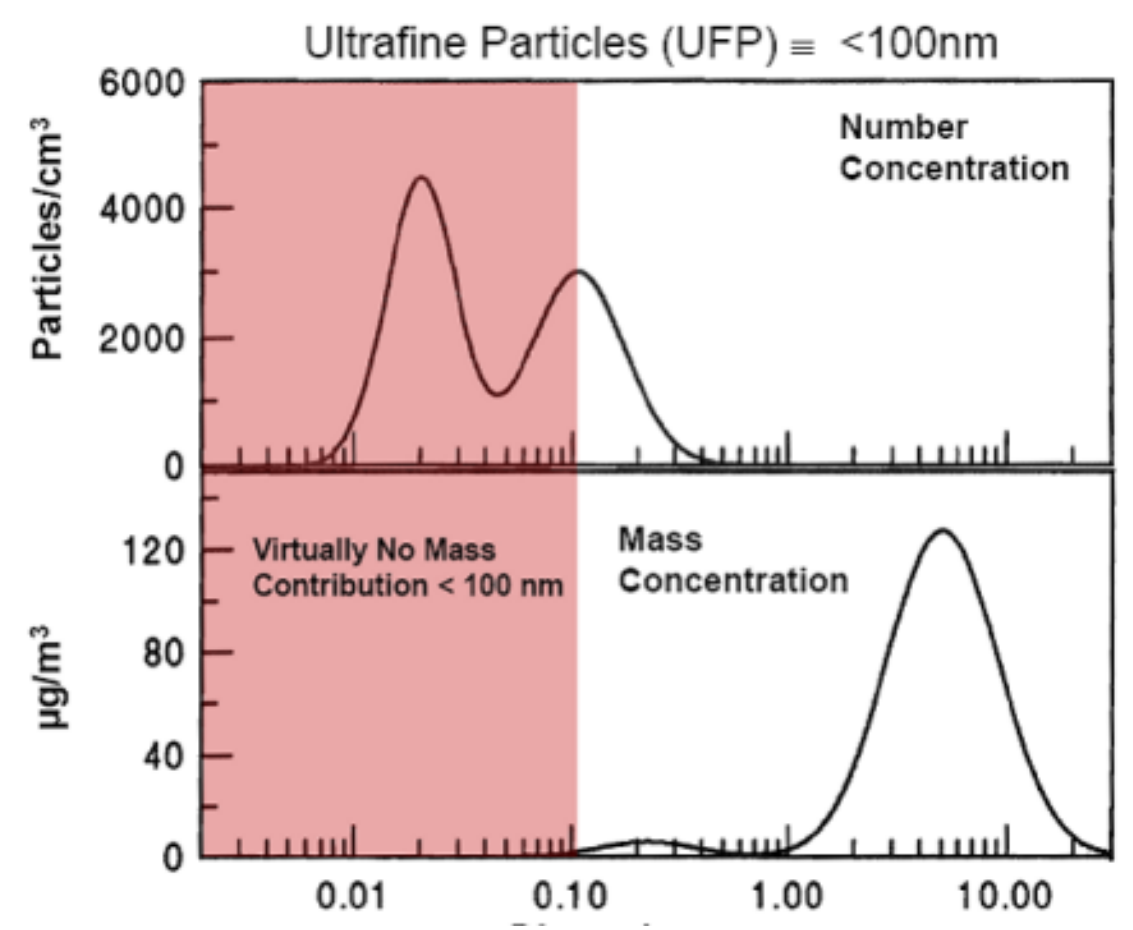

Diameter, $\mu \mathrm{m}$

Figure 1.2 Particle number and size distribution in ambient air (Seinfeld and Pandis, 1998)[9]

Morawska et al. (2008)[10] compared particle concentration levels from 71 measurements studies for different outdoor environments and calculated the mean and median values for each category were calculated using available literature data (Figure 1.3). The highest concentration was reported in tunnel environments followed by on road and roadside environment. On road and roadside mean concentrations were higher by 27 and 18 times respectively than a clean background. These results show 
that, vehicle emissions are commonly the most significant source of UFP pollution in populated urban areas. It is therefore of particular significance to understand the magnitude and characteristics of the vehicle-affected UFPs in urban air, as it is this type of environment which is the most likely to be considered as a target for future air quality regulations in relation to particle number.

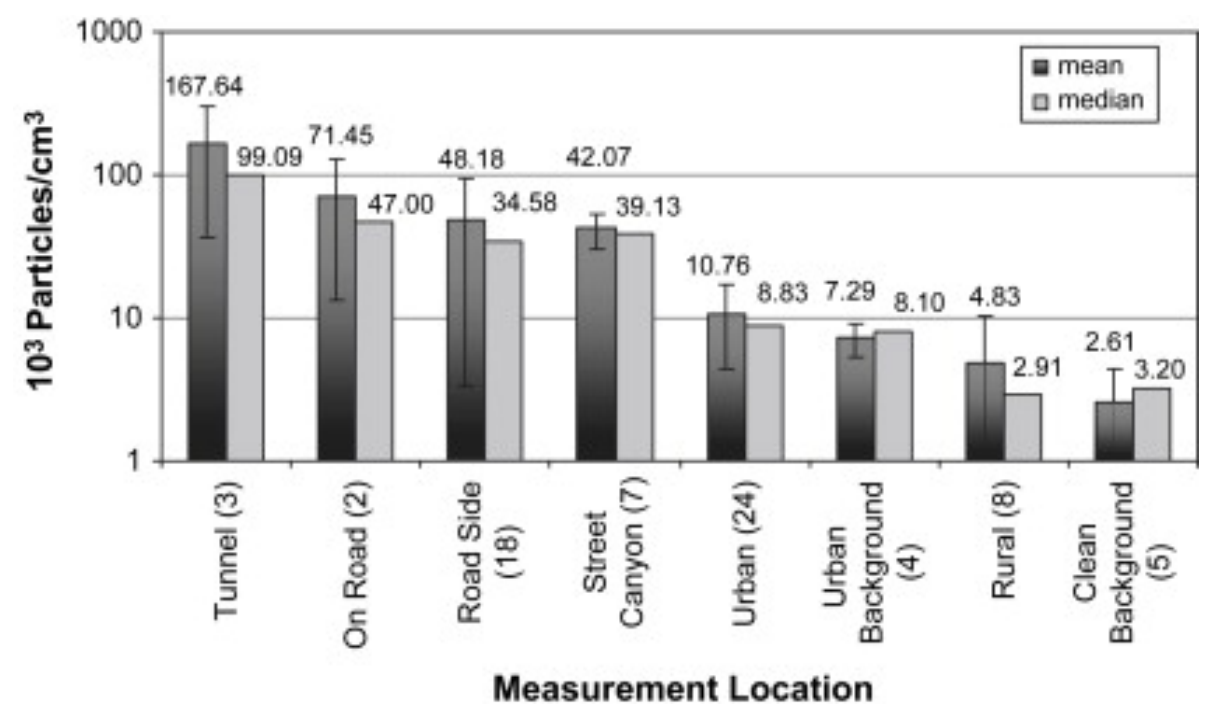

Figure 1.3 Mean and median values of UFP number concentration at different outdoor environment (Morawska et al., 2008)[10]

These results show that, vehicle emissions are commonly the most significant source of UFP pollution in populated urban areas. It is therefore of particular significance to understand the magnitude and characteristics of the vehicle-affected UFPs in urban air, as it is this type of environment which is the most likely to be considered as a target for future air quality regulations in relation to particle number. 
UFP chemical composition varies over time and space due to changing source impacts, processed leading to formation and growth of particles and meteorology. EPA's PM Supersite Program (Solomon et al., 2008)[11] found Organic Carbon as a major fraction of UFP at most measurement locations. Morawska et al. (2008)[10] also studied the composition of UFP at a number of locations and found that UFP composition varied by location with Organic carbon, sulfate, and elemental carbon constituting the major part of the composition.

\subsection{Sources of Ultrafine particles in urban environment}

Due to the abundance of various complex pollution sources emitting particulate matter and gaseous co-pollutants, heavily populated urban areas are considered important hotspot of urban air pollution. Ultrafine particles are ubiquitous in urban environments (Kumar et al., 2014)[12]. Various studies have focused on the source apportionment of number and size distribution of ultrafine particles in urban air (Pey et al., 2009)[13]; Costabile et al., 2009[14]; Harrison et al., 2011[15]; Dall'Osto et al., 2012[16]; Hussein et al., 2014[17]; Liu et al., 2014[18]; Salimi et al., 2014[19]). Emission inventories suggest that, in urban environment the major contribution to the fine and ultrafine particles comes from anthropogenic combustion activities, namely from emissions of industrial combustion processes and traffic-related emissions (Schauer et al., 1996[20], Shi et al., 1999[21], Cass et al., 2000[22], Harrison et al.[23], 2000 and Hitchins et al., 2000[24]). Secondary particles generated by the photochemical or 
physical processes in the atmosphere are also important processes contributing to urban particle number concentration (Fine et al., 2004[25] and Zhang et al., 2004[26]).

A source emissions inventory (1996) constructed for the South Coast Air Basin that surrounds Los Angeles shows the contributions of major combustion sources to total estimated UFP emissions. On-road motor vehicles, stationary source fuel combustion, non-highway mobile sources (for example diesel off-road vehicles) appear as the largest sources of urban UFP (Figure 1.4).

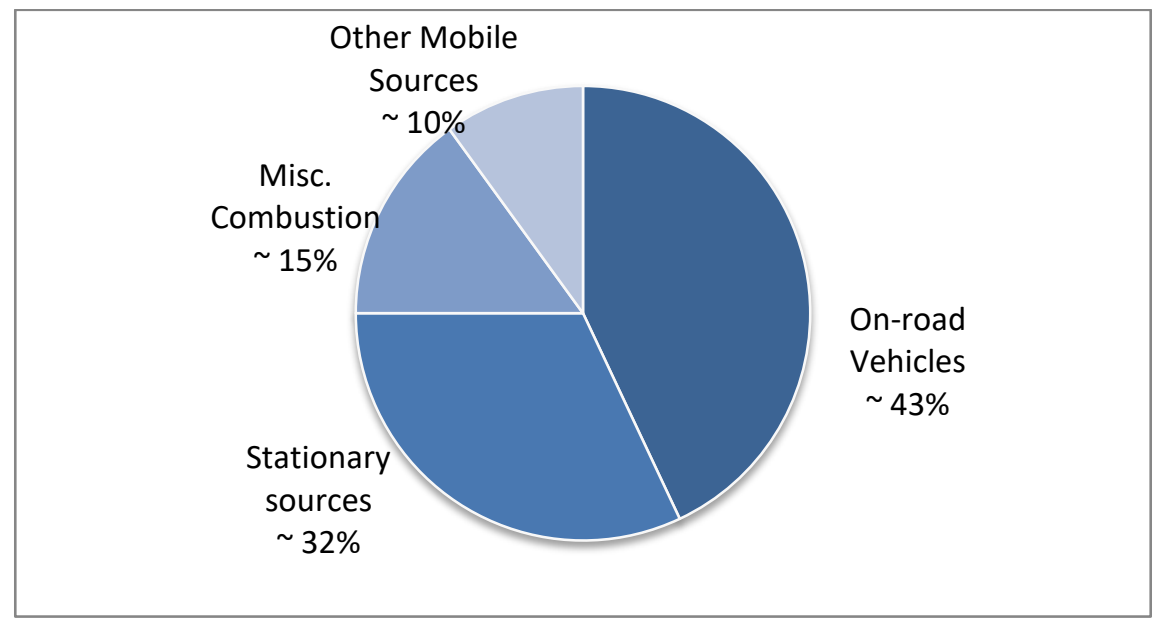

Figure 1.4 Major Combustion Sources of Ultrafine Particles. (Cass et al., 2000) [27]

Studies have shown that in polluted urban environment, road vehicle may contribute up to $90 \%$ of the total particle number concentration. (Pey et al., 2009[28]; Kumar et al., 2010[29]). Particle number concentrations as well as their size distribution show high spatial variability within a city, which is mostly related to the presence of strong local 
sources such as road traffic emissions, and to the short lifetime of UFP (Ketzel et al., 2004 [30]; Tuch et al.,2006 [31]; Pohjola et al., 2007 [32]; Wang et al., 2011 [33]). Therefore, it is important to quantify and characterize on road UFP emission factors and to understand various chemical and physical processes that affect UFP behavior after emission as they are transported away from the emission sources, such as busy roads and highways.

\subsection{Ultrafine Particles in near roadway environment}

Several studies have identified direct emissions from roadway traffic and secondary particles generated by the photochemical or physical processes as the dominant source of ultrafine particles in the outdoor environment (Fine et al., 2004 [25]; Zhang et al., 2004[26]. The majority of particulate matter emitted through vehicle tailpipe exhaust occurs in the PM1.0 (diameter $<1 \mu \mathrm{m}$ ) size range, with mass median diameter generally between 100 and 200 nm (Kleeman et al., 2000 [34]; Robert et al., 2007a,b [35], [36]) and number median diameter around $20 \mathrm{~nm}$ (Janhall et al., 2004 [37]; Kittelson et al., 2004 [38]). Due to the proximity to emission sources, UFP concentrations are highest in the near-roadway locations and have a magnified response to such emissions in comparison to larger particle sizes (Molnar et al., 2002 [39]). Various roadside studies have reported high concentration of UFP associated with freeway driving. The Air resources board of California EPA has estimated that over $50 \%$ 
of a person's daily exposure to ultrafine particles can occur during daily commute on a freeway. This suggests that near roadway exposures may play an important role in the overall UFP exposure assessments.

Strength of emission from the roadway and various atmospheric processes affecting the fate and transport of these particles are key processes that determine the near roadway number concentration of UFPs.

\subsubsection{Emissions of ultrafine particles from vehicles}

Particles emitted from diesel engines are in the size range 20-130 nm (Kittelson, 1998 [40], Morawska et al., 1998a [6], Harris and Maricq, 2001 [41] and Ristovski et al., 2006 [42]) and from petrol engines in the range 20-60 nm (Harris and Maricq, 2001 [41] and Ristovski et al., 2006 [42]). Therefore, a large fraction of the particle number concentration in urban air is found in the UF size range. Kirchstetter et al. (1999) [43] measured particle emissions from light and heavy duty vehicles and found that heavy duty vehicles emits 15-20 times the number of particles per unit mass of fuel burned compared to light duty vehicles. Combustion technology also affects PM emissions with diesel vehicles emitting higher PM in terms of both number and mass concentrations (Figure 1.5). 


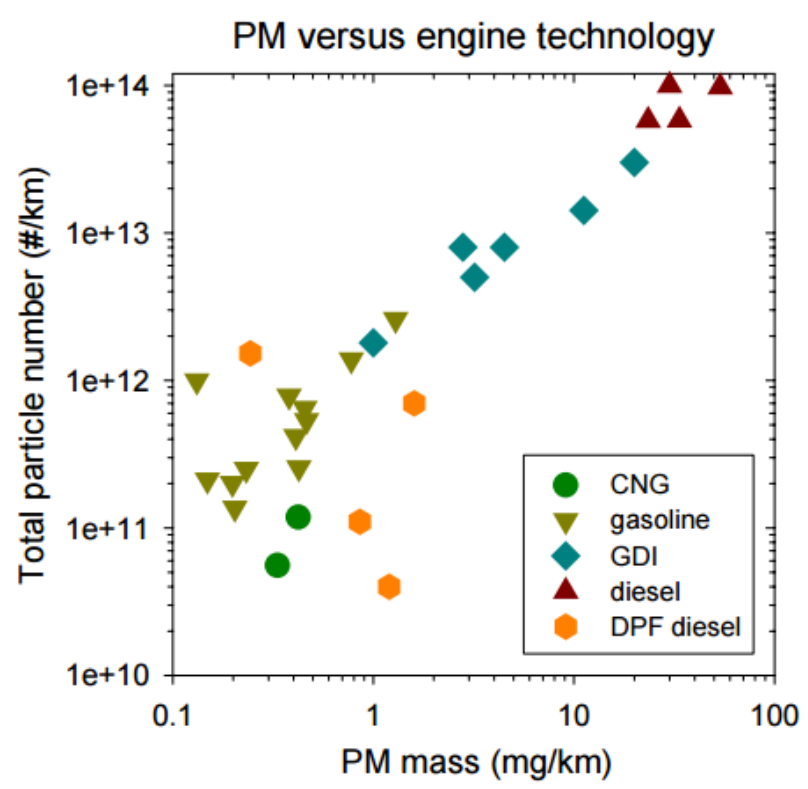

Figure 1.5 Particle mass and number concentrations from various engine technologies: Compressed Natural Gas (CNG), Gasoline engine, Gasoline Direct Injection (GDI), Diesel engine, Direct Particulate Filter (DPF). [44]

Emission of UFP from vehicles can be classified as primary and secondary particles. Particles can be formed in the engine or tailpipe (primary particles) or they can be formed in the atmosphere after emission from the tailpipe (secondary particles).Primary particles are emitted directly into the atmosphere from vehicle tailpipe and often include aggregates of smaller particles. This primary fraction is typically the dominating concentration in roadside environment and contains particles in the size range of 50 and $100 \mathrm{~nm}$ (Wahlin et al., 2001 [45]). These primary particles can grow into the near accumulation range 60-100 nm (Karasev et al., 2004 [46]) by coagulation and depositional mechanisms (Zhang et al., 2004) [26]. Larger particles (>300-1000 nm in 
diameter) typically represent aged primary particles upon which water and secondary mass has accumulated (Ondov and Wexler, 1998) [47].

Secondary particles are formed when hot exhaust gases expelled from vehicle tailpipe rapidly cools in the ambient atmosphere and causes formation of new particles through the condensation of low volatility constituent gases. They are volatile and consist mainly of hydrocarbons and hydrated sulphuric acid. These very small particles compose the nucleation mode and are in the size range below $30 \mathrm{~nm}$. Secondary particles have been commonly observed near busy freeways, especially carrying a large fraction of heavy duty diesel vehicles (Harrison et al., 1999 [48], Charron and Harrison, 2003 [49], Sturm et al., 2003 [50], Gramotnev and Ristovski, 2004 [51], Zhu et al., 2004, Rosenbohm et al., 2005 [52], Westerdahl et al., 2005 [53] and Ntziachristos et al., 2007 [54]).

UFP emission from vehicle tailpipe also varies with the nature of fuel composition, operating conditions and control strategies. Earlier studies have focused on the sulfur content in fuel, which during combustion gets oxidized to sulfuric acid and is emitted as volatile material. In the ambient atmosphere, sulfuric acid undergoes various atmospheric processes and contributes to total particle emissions. The move to ultra low sulfur fuel, fully phased nationwide in 2010 has substantially lowered emissions of particulate matter from diesel engines. The recent introduction of biofuels in heavy duty diesel vehicles is an important step towards decreasing the reliance on 
fossil fuels and hence mitigating climate change. Although the use of biofuels has reduced the overall mass concentration of fine particles, the number concentration of UFP has increased due to the reduced surface area of pre existing particles. A study conducted in East Germany investigated the temporal changes in the mass and number concentration of different particle sizes from 1993 to 1999 and found that changes in combustion technology resulted in greater emissions of UFPs (Pitz et al., 2001). It was concluded that the optimized combustion processes lead to the rise in the very small UFP number concentration $(<0.03 \mu \mathrm{m})$ both by direct emissions and by the diminished "scavenging effect" of coagulation (Pitz et al., 2001) [55].

\subsubsection{Environmental fate and transport of vehicle generated UFPs}

After UFPs are emitted into the atmosphere from vehicle tailpipe, they undergo various atmospheric processes (summarized in Table 1.2) which govern their fate and transport. These atmospheric processes depend on ambient meteorological conditions such as, wind speed, temperature, relative humidity and solar radiation.

Table 1.2 Effect of various atmospheric processes on UFP number and size

\begin{tabular}{ccc}
\hline Process & Effect on Particle number & Effect on particle size \\
\hline Nucleation & Increase & No particle to new particle \\
Dilution & Decrease & Preserved \\
Condensation & Conserved & Increase \\
Evaporation & Decrease & Decrease \\
Coagulation & Decreases number of smaller & Increase \\
& particles & \\
Deposition & Decrease & Variable \\
\hline
\end{tabular}


The dispersion of UFP into the atmosphere is primarily dependent on the diluting effect of wind. High wind speeds cause efficient mixing and transport of pollutants, resulting in lower concentrations. Atmospheric stability also affects the vertical movement of air parcels and hence affects dispersion.

Dilution with background air is the main dynamic mechanism influencing number concentrations. Zhang and Wexler (2004) [26]; Ketzel, (2003) [56] demonstrated that the dilution of the emitted exhaust can occur in two distinct stages. The first stage dilution, from tailpipe-to-road, results in the dilution of UFP up to a factor of 1000 and is caused by the traffic turbulence within 1-3 s immediately after emission from the vehicle tailpipe. The second stage of dilution, from roadway-to-ambient environment, is mainly caused by atmospheric turbulence. This results in further dilution of the concentration of UFPs by about a factor of 10 and usually lasts 3-10 min. These large dilutions cause the exponential decay of UFP within relatively small distances away from freeways. Hitchins et al. (2000) [24] showed that at a distance 100-150 m from roadways, concentration of UFP decayed to around half the values measured at a near road location when the wind is blowing directly from the road.

After dilution, three main processes- nucleation, condensation and coagulation (Figure 1.6)- affect the number and size distribution of UFP and operate over vastly different characteristic times. Further, these processes have varying importance for different sized particles. Nucleation is ubiquitous in ambient air and causes the formation of new particles through super saturation of low volatility gases emitted 
during combustion processes. Particles formed through nucleation are generally below $20 \mathrm{~nm}$ in size (Kulmala et al., 2004) [57]. Low temperature and high relative humidity favors the formation of nuclei mode particles (Ronkko, et al. 2006) [58].

Growth of these small particles is often by condensation of such super saturated compounds on pre- existing particles. Thus nucleation and condensation are two competing processes where nucleation is favored when UFP concentrations are low, whereas, in polluted environment, condensation is favored due to high pre-existing surface area (Alam et al., 2003)[59].
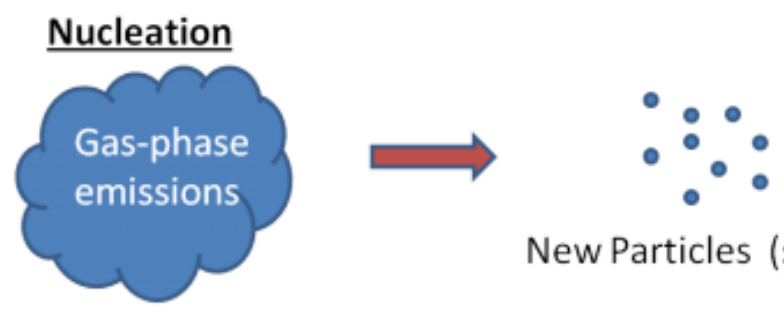

New Particles (size less than $20 \mathrm{~nm}$ )

\section{Condensation}
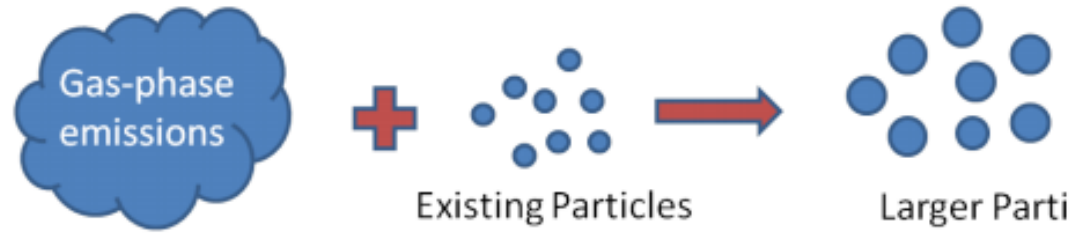

Existing Particles

Larger Particles

\section{Coagulation}

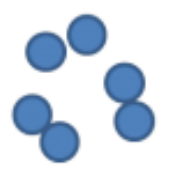

Existing Particles

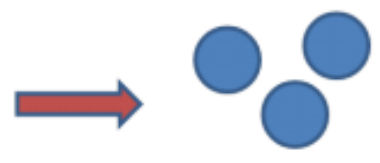

Larger Particles

Figure 1.6 Illustration of Nucleation, condensation and Coagulation processes 
Particles are further transformed through coagulation whereby growth occurs through collisions between particles of the same or different sizes. Nucleation mode particles have short atmospheric lifetimes of about a few minutes since they coagulate with other particles to form new particles. These processes are important considerations when studying the spatial variability of UFP number and size distribution for exposure assessment. Near roadways, there are many small particles $(\sim 30 \mathrm{~nm})$ that are derived from traffic sources. As distance from the roadway increases (100-300 m from the road), the number of small particles decreases due to evaporation and growth processes and the UFP size distribution is dominated by larger particles $(60 \mathrm{~nm})$.

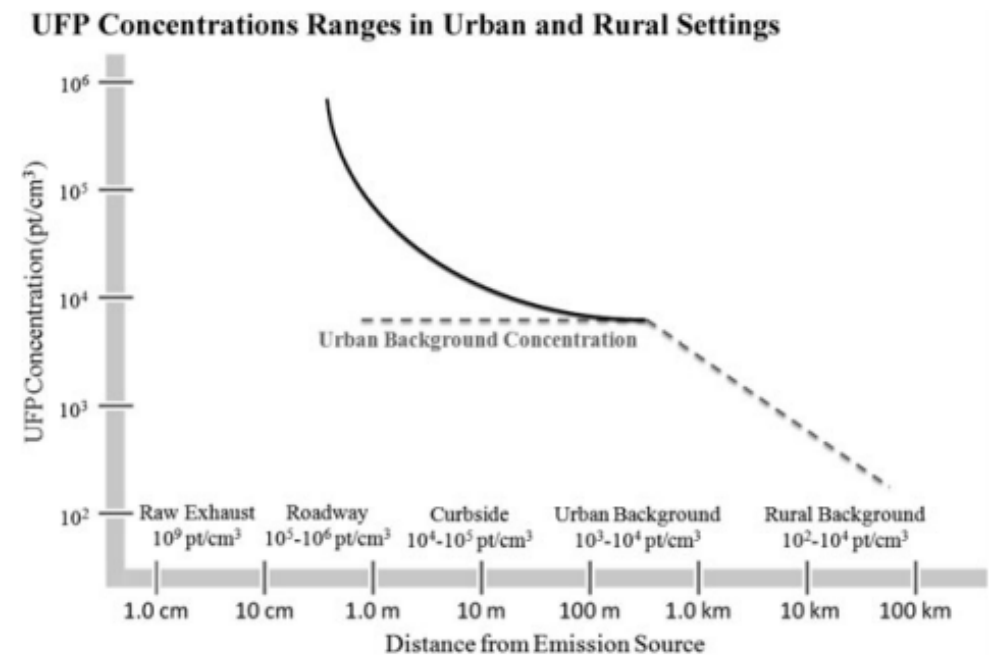

Figure 1.7 The range of UFP concentrations reported in the literature for various spatial scale (K. Sabaliauskas and G. Evans ,2010 [60]) 
K. Sabaliauskas and G. Evans (2010) [60] summarized the UFP concentration ranges at various spatial scales based on studies conducted in urban and rural settings throughout the world and demonstrated that, depending on an individual's location within a city, the outdoor UFP number concentration can vary by as much as three orders of magnitude with the highest observed near roadways (Figure 1.7).

\subsubsection{Factors affecting ear roadway exposure}

Individuals spend a significant portion of their time spent outdoor near traffic sources such as walking along high traffic roads, waiting at intersections, sitting in vehicles with the windows open, or working in buildings near traffic. Almost more than 45 million people in the United States live, work, or attend school within 300 feet of a major road, airport or railroad (US EPA). Particle number concentrations (PNC) can reach up to 30 times near roadways than the local background levels and decay exponentially at distances downwind from highways and reaches background levels at distances beyond 300 m(Morawska et al., 2008[10]; Zhang and Wexler, 2004[61]). Zhu et al. (2002b) [62] and Kittelson et al. (2004) [38] have found that nuclei sized particles with diameters less than $50 \mathrm{~nm}$ are dominant at a roadside site but absent at a background site. So individuals are exposed to elevated levels of UFP number concentrations during their time spent near roadways than what is typically observed further away from roadways. Near roadway exposure to UFP also shows temporal variation over very short time scales. During the daily commute of an individual along a major road, he or she is 
exposed to a combination of an urban background concentration as well as spikes of UFP caused by passing of diesel vehicles. These UFP concentration spikes usually last for 1-2 min. Therefore, these UFP concentration spikes are important consideration while assessing exposure of individuals sitting in vehicles with the windows open, and when walking or cycling along major arterial roadways. Figure 1.8 illustrates the transition from a roadway with 25,000 vehicles per day to one with less than 2000 vehicles per day and the corresponding variation in UFP concentration (K. Sabaliauskas and G. Evans, 2010) [60]. On the high traffic road, frequent UFP spikes are observed. These spikes correspond to passing of diesel vehicles. On the other hand, the frequency of spikes is fewer on the low traffic roads due to fewer diesel-powered vehicles. A constant UFP baseline or urban background concentration is observed in both locations that vary both temporally and spatially but over much larger and longer time scales than the spikes.

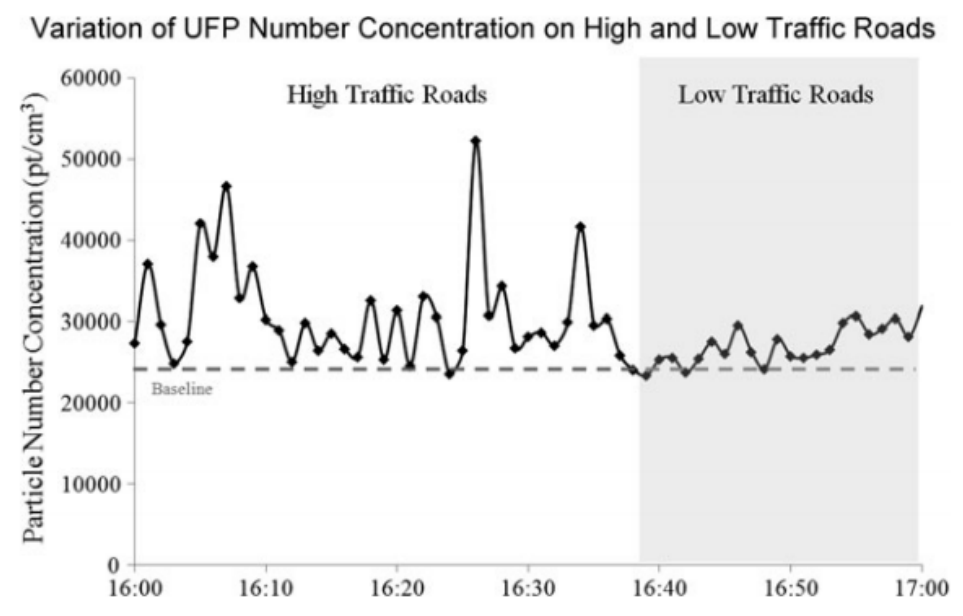

Figure 1.8 The variation of UFP number concentration while walking along high and low traffic roads in Toronto, Canada (K. Sabaliauskas and G. Evans, 2010)[60]. 


\subsection{Health Impacts of ultrafine particles}

Exposure to PM, produced from combustion may lead to adverse health effects including various cardiovascular and respiratory diseases (Pope and Dockery, 2006)[2]. Several epidemiological studies have hypothesized that the observed health effects associated with atmospheric PM are actually caused by the ultrafine portion of PM (Brugge et al., 2007 [63]; Hoek et al., 2010 [64];, Nawrot et al., 2007) [65]. Several studies have found significant associations between exposure to ultrafine PM and respiratory, cardiovascular disease and mortality in susceptible people (Wichmann et al., 2000 [66]; Peters et al., 1997a [67], 1997b [68]; Penttinen et al., 2001 [69]; von Klot et al., 2002 [70]; Pekkanen et al., 2002 [71]). However, some epidemiologic studies have not found associations between UFP exposure and health effects (de Hartog et al. 2003) [72].

Unlike larger particles which are removed by the defense mechanism of mucociliary system (Daigle et al. 2003 [4]), UFPs have a higher probability of penetrating deep into the lungs due to their small size and depending on their size they can efficiently deposit on nasal, tracheobronchial, and alveolar regions due to diffusion (Figure 1.9). Below $0.1 \mu \mathrm{m}$, deposition increases since diffusion becomes more efficient with decreasing particle size (ICRP, 1994) [73].

UFPs can enter the circulatory system (Nemmar et al., 2002 [74], Oberdörster et al., 2002 [75], Kreyling et al., 2004 [76]) and move from the lungs to other critical organs 
such as the heart and brain. UFPs contain little mass, but possess a large surface area (high surface reactivity) because they occur in high numbers.

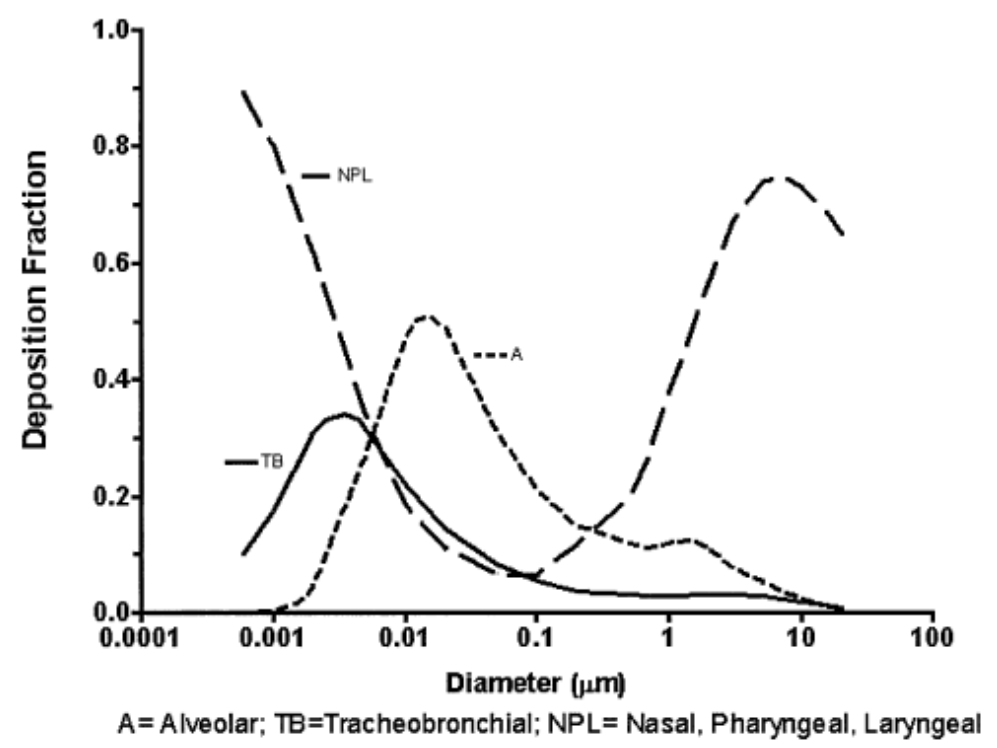

Figure 1.9 Predictions of the ICRP (1994)[73] model in terms of the fractional deposition in each region as a function of the size of the inhaled particles.

At a given mass, ultrafine particles have $10^{2}$ to $10^{3}$ times more surface area than larger particles with diameters in the $0.1-2.5 \mu \mathrm{m}$ range and approximately $10^{5}$ times more surface area than coarse particles $(2.5 \mu \mathrm{m}<$ diameter $<10 \mu \mathrm{m})$ (Harrison et al., 2000) [23]. The larger surface area increases the toxic properties of UFPs and will impact a larger surface area of lung tissue than will an equal mass of larger particles. Studies have claimed ultrafine particles to be are more toxic than larger particles with the same chemical composition per given mass by inducing more oxidative stress than fine particles (Li et al., 2003 [77] and Stone et al., 2000) [78] and causing more proinflammatory responses than larger particles (Donaldson et al., 2001 [79] and 
Donaldson et al., 2002 [80]). Thus, number concentration of ultrafine particles is needed for better assessment of ambient air quality and its potential health effects.

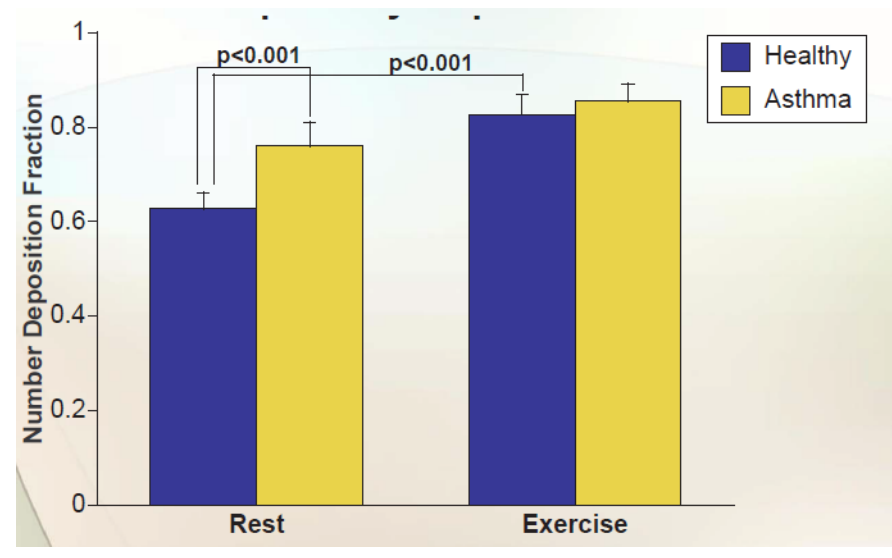

Figure 1.10 Particle number deposition fraction at rest and exercise in healthy and asthmatic subjects (Chalupa et al,. 2004)[81]

Human exposure studies have shown that certain sensitive sub-populations like Individuals with chronic obstructive pulmonary disease may be more susceptible to the adverse health effects due to exposure to UFP. Chalupa et al. (2004)[81] showed that people with asthma have a higher total respiratory dose of UFPs for a given exposure than healthy people (Figure 1.10).

Therefore, a detailed understanding of UFP near the major sources- busy roads and road networks is an essential and urgent issue. This study involves measurement of UFP, various co-pollutants ( $\mathrm{NO}, \mathrm{NO}_{2}, \mathrm{PM}_{2.5}$ mass) and meteorological parameters (wind speed, direction and temperature). Simultaneous traffic volume was also collected. Currently there are not many UFP monitors deployed in the governmental monitoring 
stations. On the other hand, regulated gaseous pollutants and particle mass monitors are spread all over the US.

The aim of this study is to explore the potential for predicting UFP exposure on the basis of concurrent measurement of co-pollutants by assessing the relationship between UFP and the regulated co pollutants under various meteorological conditions and developing indirect estimation of UFP emission factors under real-world conditions. The objectives of this study include: i) To explore the potential for predicting UFP exposure on the basis of concurrent measurement of co-pollutants by assessing the relationship between UFP and the regulated co pollutants under various meteorological conditions and ii) Using existing and easily available emission inventory for traffic related tracer gases to develop a less complex, indirect approach of determining real world emission factors from vehicles to be used in air quality models. 
CHAPTER 2: Characterizing Roadside Ultrafine Particle Number Concentration and Correlation with traffic related pollutants.

\subsection{Introduction}

Various epidemiological studies have linked exposure to Ultrafine Particles (UFP; diameter $100 \mathrm{~nm}$ ) to numerous adverse health impacts. UFPs 'escape' existing mass based particulate matter $\left(\mathrm{PM}_{2.5}\right.$ and $\left.\mathrm{PM}_{10}\right)$ standards as they contain little mass, but they occur in high numbers and possess a large surface area (high surface reactivity), making them more toxic than larger particles with the same chemical composition per given mass. Thus particle number concentration (PNC) is a more useful metric for UFPs in terms of exposure assessment for epidemiological studies than mass concentrations.

Roadway traffic is one of the major sources of UFPs and heavily influences air concentrations in the nearby vicinity of a major roadway depending on the strength of emission from the roadway and various meteorological processes affecting the fate and transport of these particles. Therefore exposure to UFPs near busy highways and other major roads is a topic that deserves additional research and attention.

Despite a significant body of suggestive evidence linking UFPs to adverse health effects, there are currently no legal ambient standards. At present, there lacks large scale monitoring networks for measuring number concentration of particulate matter in the United States and thereby exists a gap in our knowledge of the understanding of UFPs and exposure assessment. On the other hand, mass concentrations of nitrogen 
oxides (NO, $\mathrm{NO}_{2}$ ), Ozone $\left(\mathrm{O}_{3}\right), \mathrm{PM}_{2.5}$, Carbon monoxide $(\mathrm{CO})$ is regulated pollutants and monitors are spread all over the country. Therefore the possibility to correlate UFP number concentration with data derived from easily available and existing monitoring networks was investigated. While UFPs are generally known to be strongly influenced by traffic emissions, the characteristics of traffic-produced UFPs, relationship to co-emitted pollutants, and meteorological impacts are areas of needed research.

Continuous measurements of UFP number concentration and mass concentrations of $\mathrm{NO}, \mathrm{NO}_{2}$ and $\mathrm{PM}_{2.5}$ were collected near an arterial road and freeway at different seasons and meteorological conditions and integrated with traffic count data. Statistical correlation and variability due to meteorology in relationships between UFP number concentration and various co-pollutants was examined to serve as proxyindicators for estimating UFP concentrations.

So the aim of the study is to explore the potential for predicting UFP exposure on the basis of concurrent measurement of co-pollutants by assessing the relationship between UFP and the regulated co pollutants under various meteorological conditions. The findings from this chapter have valuable implication in constructing emission inventory for PNC based of the existing emission inventory of regulated gaseous pollutants. 


\subsection{Methods}

\subsubsection{Site description and measurements}

Continuous measurements of ultrafine particle number concentration (PNC) and mass concentrations of $\mathrm{NO}, \mathrm{NO})$, fine particle mass $\left(\mathrm{PM}_{2.5}\right)$ was conducted near an arterial road and freeway at different seasons and meteorological conditions.

The measurements near the arterial road were collected by Dr. Christine Kendrick as part of her doctoral dissertation [82]. The traffic intersection located at the southwest corner of SE Powell Boulevard and SE 26th Avenue in Portland, Oregon USA, includes a diverse mix of road users (including freight, public transit, pedestrians, cyclists and passenger vehicles). SE Powell Boulevard is a major arterial roadway that runs east/west with peak hourly traffic volumes of 2,800 vehicles and Average Annual Daily Traffic (AADT) of 28,000 vehicles per day, including $6 \%$ trucks on weekdays. Concentration was measured for 339 hours spanning from September, 2013 to April, 2014. Measurements were performed at different times of the day, on different days of the week, and in different seasons of the year. Therefore the dataset contains measurement from a wide range of traffic and meteorological conditions in order capture temporal variation due to differences in meteorology and pollutant source

strength. Traffic volumes in fifteen minute bins for each lane were collected using inductive loop detectors and the Sydney Coordinated Adaptive Traffic System (SCATS) 
infrastructure which is an adaptive signal system that operates on a 3.7 mile stretch of Powell Blvd including the study intersection [83].

Continuous measurements of various traffic pollutants ( $\mathrm{NO}, \mathrm{NO}_{2}, \mathrm{PNC}, \mathrm{PM}_{2.5}, \mathrm{CO}$ ) from the freeway was collected from Oregon Department of Environmental Quality's near road air monitoring station located near interstate 5 (I-5) at SW Bradbury court, Portland, USA. Total 270 hours of measurement spanning from May, 2016 to September 2016 was conducted. I-5 is the main Interstate Highway on the West Coast of the United States, running largely parallel to the Pacific coast of the continental U.S. It is the main north-south interstate highway route across the metro Portland area. An estimated onroad vehicle fleet from the $1-5$ freeway in Portland, Oregon, for 2010 includes $8.9 \%$ of the fleet made up of heavy duty diesel vehicles, similar to the U.S. average of $8 \%$ of vehicle miles traveled by trucks on urban freeways[84]. The peak hourly traffic volume is approximately 7000 vehicles and Average Annual Daily Traffic (AADT) is 151,500 vehicles per day. The traffic count and speed data was accessed from the Portland Oregon Regional Transportation Archive Listing (PORTAL) at 15 minute bins.

Teledyne T200 chemiluminescence $\left(\mathrm{NOx}=\mathrm{NO}+\mathrm{NO}_{2}\right)$ analyzer was used to monitor $\mathrm{NO}$ and $\mathrm{NO}_{2}$. PM 2.5 was monitored using a TSI DRX DustTrak monitor. Particle number measurements were done by using TSI P-Trak particle counter (TSI Model 8525) in the size range from $0.02 \mu \mathrm{m}$ to over $1 \mu \mathrm{m}$. The P-TRAK is a portable condensation particle counter that draws air through a saturator tube soaked with isopropyl alcohol operating at a constant flow rate of $100 \mathrm{~cm}^{3}$ per minute. The isopropyl alcohol 
condenses on the particles causing them to grow large enough to be detected optically by passing them through a focused laser beam producing flashes of light which are counted using a photo detector. PNC measurements were made typically from 5 am to 10:30 pm and the alcohol wick was recharged every 6 hours.

The sampling inlet at both sites was placed at approximately $2.5 \mathrm{~m}$ above the ground to ensure minimum disturbance from the street but still capturing road emissions at the street level.

\subsubsection{Regression analysis}

Correlation coefficients were calculated to investigate the associations of PNC to the other pollutants and traffic volume for both 15 minute and 1 hour averages. Linear regression analysis was performed to qualitatively explore the impact of meteorological parameters on PNC, NOx and their ratio. These analyses were performed using statistical software R.

While investigating the relationship between pollutants and meteorological parameters (i.e. wind speed and ambient temperature), hourly averages of PNC, NOx and PNC-NOx ratio were grouped within temperature and wind speed bins. The wind speed and temperature bins were created using steps of $0.5 \mathrm{~ms}^{-1}$ and 2 degree $\mathrm{C}$ respectively. The median of the values within each bin was calculated for each 
parameter. This process eliminates the impact of any extreme value within the bins and allows the use of linear regression to explain the relationship. This analysis uses measurements only when the wind direction was coming from the road. In the arterial road this will be referred to as the road wind direction bin which includes $270^{\circ}$ (W) to $360^{\circ}(\mathrm{N})$ and $0^{\circ}(\mathrm{N})$ to $125^{\circ}(\mathrm{SE})$ in order to capture arterial traffic influences. For freeway, measurements when wind was blowing from $180^{\circ}(\mathrm{S})$ to $360^{\circ}(\mathrm{N})$ was considered for analysis.

\subsection{Results}

2.3.1 Relationship of Ultrafine particle number concentrations with traffic volume and co-pollutants.

Mean, median, 5th and 95th percentile values of roadside ultrafine particle number concentration ( $\mathrm{PNC}$ ), $\mathrm{NO}, \mathrm{NO}_{2}$ and $\mathrm{PM}_{2.5}$ for both the arterial road and the freeway is given in table 2.1. A direct comparison of the pollutant concentrations collected from the two roadway settings is not possible since measurements from the freeway and arterial road were conducted at different times of the year. The traffic characteristics of the two roadways are also very different. For a qualitative discussion the pollutants concentrations from the two roadways has been summarized by season for comparison. 
For all the pollutants, the concentration was higher in fall and winter. This increase may be attributed to the lower boundary conditions and lower wind speeds prevailing during these seasons leading to less dispersion of pollutants. Fall measurements of pollutants from the freeway were slightly higher than measurements from the arterial road during fall.

Table 2.1 Summary of roadside pollutant concentrations at 15 minute averages.

\begin{tabular}{|c|c|c|c|c|c|}
\hline & \multicolumn{3}{|c|}{ Arterial } & \multicolumn{2}{|c|}{ Freeway } \\
\hline & $\begin{array}{c}\text { Spring } \\
\text { Mean } \\
\text { Median } \\
\left(5^{\text {th }}-95^{\text {th }}\right. \\
\text { percentile) }\end{array}$ & $\begin{array}{c}\text { Fall } \\
\text { Mean } \\
\text { Median } \\
\left(5^{\text {th }}-95^{\text {th }}\right. \\
\text { percentile })\end{array}$ & $\begin{array}{c}\text { Winter } \\
\text { Mean } \\
\text { Median } \\
\left(5^{\text {th }}-95^{\text {th }}\right. \\
\text { percentile) }\end{array}$ & $\begin{array}{l}\text { Summer } \\
\text { Mean } \\
\text { Median } \\
\left(5^{\text {th }}-95^{\text {th }}\right. \\
\text { percentile) }\end{array}$ & $\begin{array}{c}\text { Fall } \\
\text { Mean } \\
\text { Median } \\
\left(5^{\text {th }}-95^{\text {th }}\right. \\
\text { percentile) }\end{array}$ \\
\hline $\begin{array}{c}\text { PNC } \\
\left(\text { Particle } / \mathrm{cm}^{3}\right)\end{array}$ & $\begin{array}{c}8972 \\
7793 \\
(3048-16332)\end{array}$ & $\begin{array}{c}14985 \\
13254 \\
(4077-40109)\end{array}$ & $\begin{array}{c}17860 \\
15609 \\
(3821-48815)\end{array}$ & $\begin{array}{c}8298 \\
7699 \\
(3175-14986)\end{array}$ & $\begin{array}{c}18947 \\
17403 \\
(4122-38729)\end{array}$ \\
\hline $\begin{array}{c}\text { NO } \\
(p p b)\end{array}$ & $\begin{array}{c}8 \\
5 \\
(0.1-25)\end{array}$ & $\begin{array}{c}12.9 \\
11 \\
(1.25-52.6)\end{array}$ & $\begin{array}{c}15.4 \\
13 \\
(1.57-59.6)\end{array}$ & $\begin{array}{c}11.5 \\
11.2 \\
(0.1-33)\end{array}$ & $\begin{array}{c}14.8 \\
13.1 \\
(1-48)\end{array}$ \\
\hline $\begin{array}{l}\mathrm{NO}_{2} \\
(p p b)\end{array}$ & $\begin{array}{c}7 \\
6.5 \\
(2-15.4)\end{array}$ & $\begin{array}{c}10.3 \\
9.6 \\
(3.1-22)\end{array}$ & $\begin{array}{c}11.2 \\
10.3 \\
(1.12-24.5)\end{array}$ & $\begin{array}{c}12.8 \\
11.2 \\
(4.5-22.3)\end{array}$ & $\begin{array}{c}14.5 \\
14.1 \\
(7.8-19.4)\end{array}$ \\
\hline $\begin{array}{c}\mathrm{PM}_{2.5} \\
\left(\mathrm{ug} / \mathrm{m}^{3}\right)\end{array}$ & $\begin{array}{c}5.8 \\
4.6 \\
(0-11)\end{array}$ & $\begin{array}{c}7 \\
5.9 \\
(1.23-12)\end{array}$ & $\begin{array}{c}14 \\
13.2 \\
(1.1-22)\end{array}$ & $\begin{array}{c}4.2 \\
3.9 \\
(2.3-7)\end{array}$ & $\begin{array}{c}4.5 \\
4.3 \\
(2.7-7.9)\end{array}$ \\
\hline
\end{tabular}

Although the average daily traffic on the freeway is almost double the average daily traffic in the arterial road, the difference in pollutant concentrations is not proportionally higher. One possible reason might be the different distances of the monitoring sites to the roadway. In the arterial road, the monitoring site is located very close to the roadway at approximately $10 \mathrm{~m}$ distance from the centerline of the road. On the other hand, the measurement site on the freeway was located at a distance of 
approximately $45 \mathrm{~m}$ from the centerline of the road. Another explanation for the higher concentration in the arterial road compared to traffic might be the presence of stop and go traffic, frequent acceleration and deceleration activity, congestion leading to the burning of more fuel (Oduyemi and Davidson, 1998 [85] and Carr et al., 2002 [86]); whereas on the freeway, the traffic generally exhibits free-flow conditions travelling at a constant speed of greater than 45 miles per hour ( $\mathrm{mph}$ ).

Simple correlation analysis was used to explore the relationship between Ultrafine PNC with traffic intensity and co-pollutants.

Table 2.2: Correlation $(p<0.001)$ of Ultrafine PNC with traffic volume and co-pollutants. (a) Arterial road; (b) Freeway.

\begin{tabular}{lllllll}
\hline & PNC & NO & NO2 & NOx & PM2.5 & $\begin{array}{l}\text { Traffic } \\
\text { Volm }\end{array}$ \\
\hline PNC & 1 & 0.64 & 0.57 & 0.63 & 0.28 & 0.33 \\
\hline NO & 0.64 & 1 & 0.74 & 0.98 & 0.43 & 0.36 \\
\hline N02 & 0.57 & 0.74 & 1 & 0.85 & 0.16 & 0.32 \\
\hline N0x & 0.63 & 0.98 & 0.85 & 1 & 0.38 & 0.38 \\
& & & & & & \\
\hline PM2.5 & 0.28 & 0.43 & 0.16 & 0.38 & 1 & 0.14 \\
& & & & & & \\
\hline
\end{tabular}

(a)

\begin{tabular}{llllllll}
\hline & PNC & NO & N02 & NOx & PM2.5 & $\begin{array}{l}\text { Traffic } \\
\text { Volm }\end{array}$ \\
\hline PNC & 1 & 0.61 & 0.53 & 0.59 & 0.23 & 0.32 \\
\hline NO & 0.61 & 1 & 0.54 & 0.98 & 0.21 & 0.29 \\
\hline N02 & 0.53 & 0.54 & 1 & 0.69 & 0.29 & 0.19 \\
\hline N0x & 0.59 & 0.98 & 0.69 & 1 & 0.25 & 0.28 \\
& & & & & & \\
\hline PM2.5 & 0.23 & 0.21 & 0.29 & 0.25 & 1 & 0.11 \\
\hline
\end{tabular}

(b)

Table 2.2 shows the Spearman correlation at 15 minute averages for PNC with traffic volume and various co pollutants (NO, $\left.\mathrm{NO}_{2}, \mathrm{PM}\right)$. Both Pearson and Spearman $15 \mathrm{~min}$ correlations are first considered, to enlighten possible linear relations (Wilks, 2006). For 
all the variables, $R_{\text {spearman }}$ value appeared as higher than $R_{\text {pearson }}$ indicating that variables are positively correlated, but not in a linear way.

The spearman correlation of PNC with $\mathrm{NO}$ ( $\mathrm{r}=0.64$ for arterial; 0.61 for freeway), $\mathrm{NO}_{2}$ ( $r=0.57$ for arterial; 0.53 for freeway) and NOx ( $r=0.63$ for arterial; 0.59 for freeway) was quite high while they remain moderate between traffic volume and PNC ( $r=0.33$ for arterial; 0.32 for freeway). The correlation between PNC and $\mathrm{PM}_{2.5}$ was very poor ( $r=0.28$ for arterial; 0.23 for freeway).

These results suggest that nitrogen oxides are better tracers for traffic-related UFP than traffic counts and $\mathrm{PM}_{2.5}$. Both nitrogen oxides and UFP are mainly emitted from combustion, whereas $\mathrm{PM}_{2.5}$ range have a variety of anthropogenic sources and $\mathrm{PM}_{2.5}$ mass does not always show the impact of local traffic emissions (Kendrick et al 2015) [82]. $\mathrm{NOx}$ is less sensitive to the $\mathrm{NO}-\mathrm{NO}_{2}-\mathrm{O}_{3}$ relationship which obviously is important for $\mathrm{NO}$ and $\mathrm{NO}_{2}$. NOx and $\mathrm{PNC}$ respond similarly to the variation of important meteorological variable such as wind speed and atmospheric stability (Grundström, M., et al .,2015 )[87].

Both roadside NOx (especially NO) and UFPs are emitted from the same source i.e. motor vehicles. To investigate why these traffic related pollutants correlate well with each other but not with traffic, we calculated correlation coefficients for these pollutants with traffic at different times of the day (Table 2.3) i.e. morning periods (5 am $-10 \mathrm{am})$ and evening periods ( $3 \mathrm{pm}-8 \mathrm{pm})$. 
Table 2.3 shows that PNC shows high correlation with NO and NOx both in the morning and evening, with morning correlation being slightly higher. The correlation between traffic volume and pollutants (i.e. PNC, NO, NOx) is comparatively higher ( $r=$ 0.58 for arterial, 0.44 for freeway) in the morning. The boundary layer is lower in the morning. This creates similar meteorological conditions. As traffic increases throughout the morning, the pollutant concentrations also increase, showing a positive correlation with traffic volume. As the day advances, boundary layer height increases, introducing higher variability in the meteorology with variable winds and dilution and thereby the correlation between traffic volume and pollutants are no longer high $(r=0.26$ for arterial, 0.14 for freeway). Since the variable meteorology in the evening affects both pollutants in the same way, the correlation between NOx and PNC is maintained high in the evening periods.

Finally the 1- hour correlation between PNC and NOx reaches, $r=0.77$ for arterial road and $r=0.69$ for Freeway, as increasing the period diminishes the influence of shortterm variations. These correlations seem strong enough to explore the potential for predicting UFP exposure on the basis of NOx measurements further. 
Table 2.3 Correlation $(p<0.001)$ of pollutants with traffic volume at different times of the day, (a) Arterial road; (b) Freeway.

\begin{tabular}{rcccccc}
\hline & \multicolumn{3}{c}{ Morning } & & \multicolumn{2}{c}{ Evening } \\
\hline & NO & NOx & $\begin{array}{c}\text { Traffic } \\
\text { Volm }\end{array}$ & NO & NOx & Traffic Volm \\
PNC & $\mathbf{0 . 7 2}$ & $\mathbf{0 . 7 4}$ & $\mathbf{0 . 5 8}$ & $\mathbf{0 . 5 9}$ & $\mathbf{0 . 6 2}$ & $\mathbf{0 . 2 6}$ \\
NO & 1 & 0.98 & $\mathbf{0 . 5 4}$ & 1 & 0.98 & $\mathbf{0 . 2 0}$ \\
NOx & 0.98 & 1 & $\mathbf{0 . 5 7}$ & 0.98 & 1 & $\mathbf{0 . 2 1}$ \\
\hline
\end{tabular}

(a)

\begin{tabular}{ccccccc}
\hline \multicolumn{3}{c}{ Morning } & \multicolumn{3}{c}{ Evening } \\
\hline & NO & NOx & $\begin{array}{c}\text { Traffic } \\
\text { Volm }\end{array}$ & NO & NOx & Traffic Volm \\
PNC & 0.63 & 0.69 & 0.44 & 0.55 & 0.59 & 0.14 \\
NO & 1 & 0.98 & 0.38 & 1 & 0.94 & 0.18 \\
NOx & 0.98 & 1 & 0.41 & 0.94 & 1 & 0.20 \\
\hline
\end{tabular}

(b)

\subsubsection{Diurnal variation of PNC and NOX with traffic volume}

Figure 2.1 shows the average diurnal variation of NOX and PNC with traffic volume. Traffic on the arterial road has a slightly bimodal distribution reflecting the morning and evening rush hours.

There is higher traffic intensity during the evening rush hour. The two peaks appear in the number of counted vehicles corresponding to the rush hours at 07:0009:00 LT (local time) and 16:00-20:00 LT. On the freeway, the morning traffic peaks 
approximately at 06.00 LT and stays consistently higher at approximately $6500-7000$ vehicles/ hour throughout the day (06.00 LT - 19.00 LT), except a small dip around $09.000 \mathrm{LT}$ to $11.00 \mathrm{LT}$.

Roadside NOx and PNC show bi-modal diurnal distribution due to a combination of changing traffic volume and meteorology. In the freeway, PNC and NOx concentrations both during the morning and evening peak periods are similarly high, with the evening peak concentrations being slightly higher. In the arterial road NOx concentrations during the evening peak was higher than the morning peak, in response to the higher evening traffic. On the other hand, higher concentrations of ultrafine particles are observed during the morning traffic peak compared to the afternoon peak despite of increased traffic volume during afternoon rush hour.

The fact that higher morning peak for PNC was observed in the arterial road is consistent with previous studies e.g.in Denmark (Wahlin et al., 2001) [45], in the United States (Woo et al., 2001) [88], in Germany (Wehner et al., 2002) [89], in Sweden (Molnar et al., 2002 [39]), and in England (Charron and Harrison, 2003) [49]. Different explanations have been advanced to explain this pattern. Wehner et al. (2002)[45] found a closer relationship between higher particle number concentrations and high traffic volumes. 


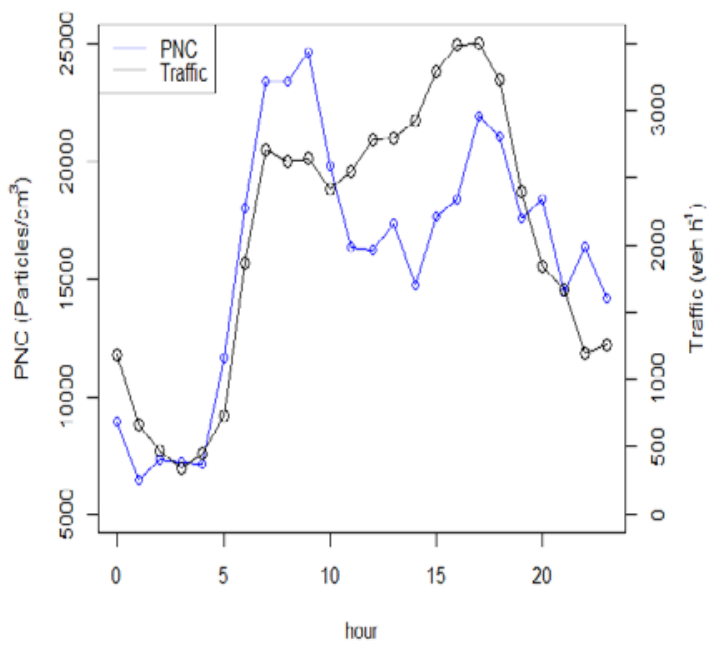

(a)

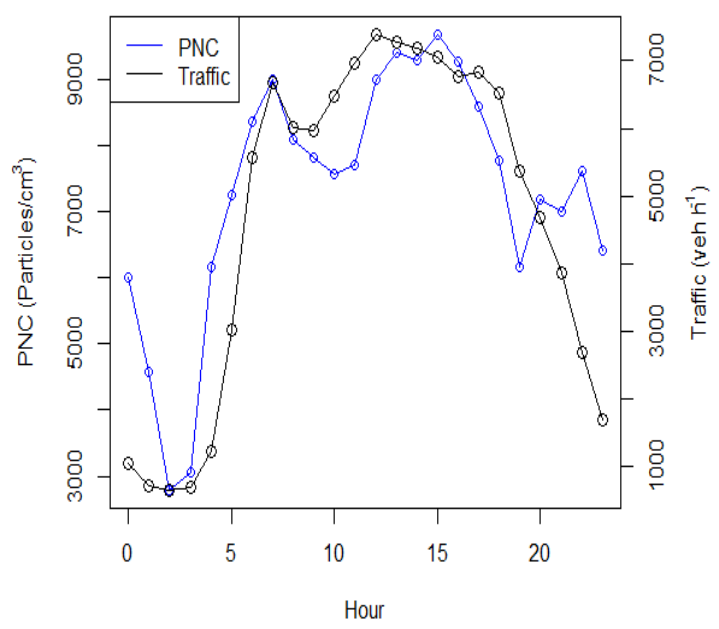

(c)

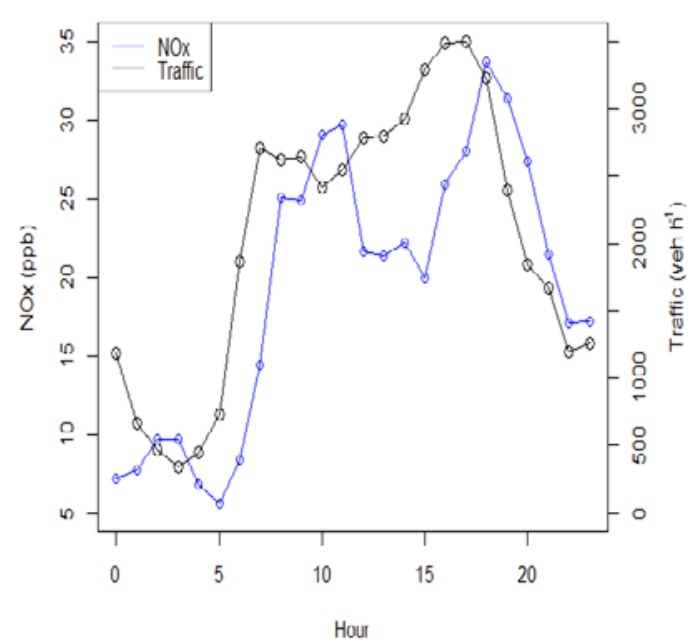

(b)

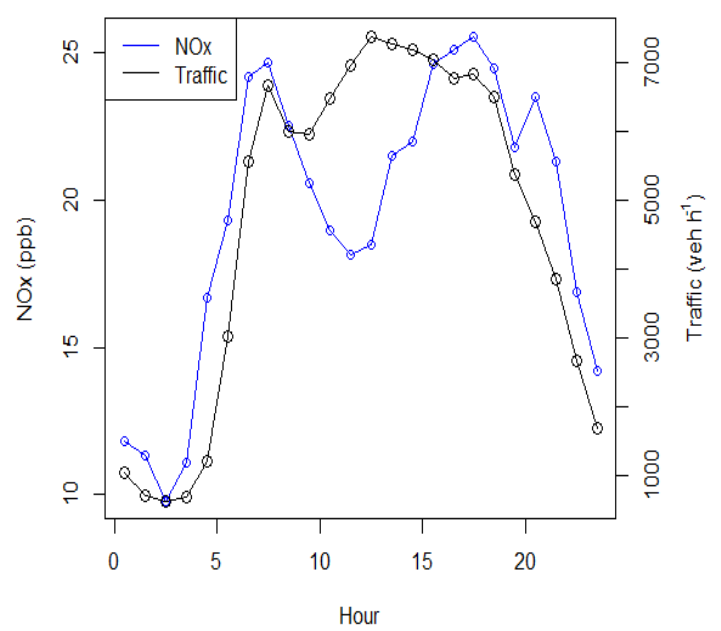

(d)

Figure 2.1 Diurnal Variation of UFP and NOx for Arterial ( $a$ and b) and Freeway (c and d)

In the case of this study, the highest concentrations in the early morning do not correspond to the highest car counts. Molnar et al. (2002) [39] have mainly attributed this result to higher wind speeds resulting in effective vertical mixing during the 
afternoon which lowered the PNC. This explanation is doubtful for this study where such dilution processes should affect NOx similarly. These results suggest that at least one another factor common to the different road sites is responsible for the high PNC in the morning.

Charron and Harrison, 2003[49] measured particle number size distribution in the range 11-452 $\mathrm{nm}$ on the side of a busy road in Central London and demonstrated that particles in the $11-30 \mathrm{~nm}$ range (nuclei mode) shows no clear relationships to traffic volumes and tend to peak in the early morning showing inverse association with air temperature. Therefore a possible explanation for the high morning peak in this study could be that the PNC measured along the arterial road in the morning mostly contains freshly nucleated particles formed as the exhaust gases are diluted with ambient air.
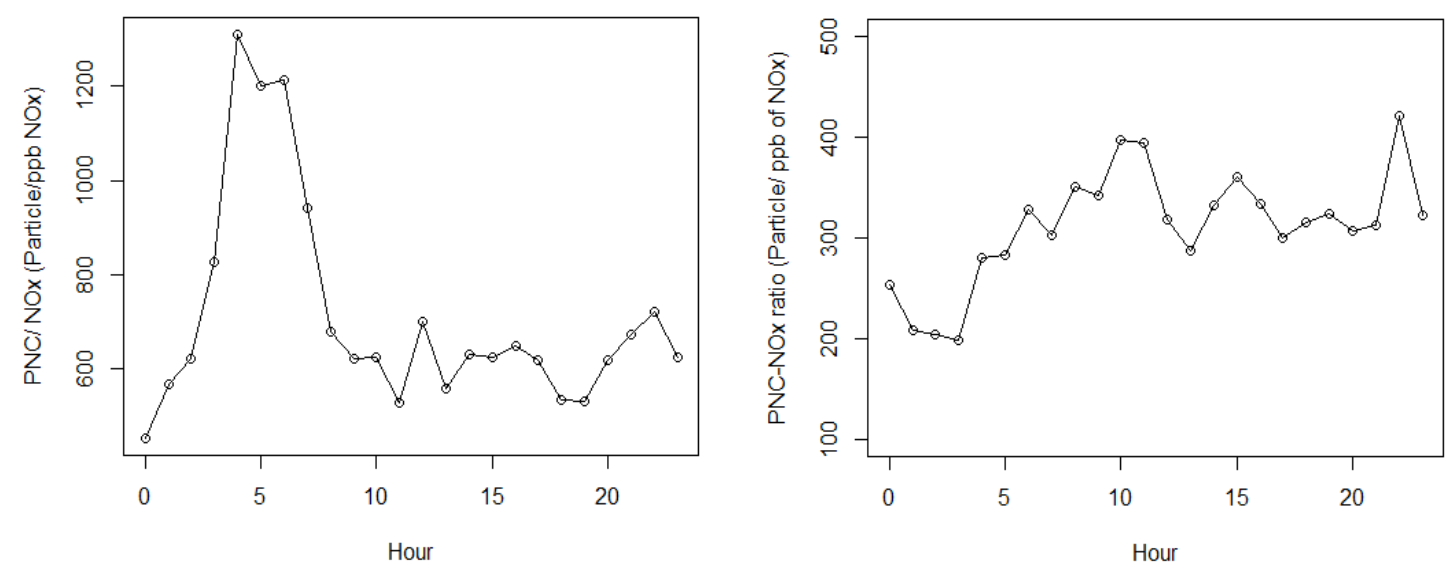

Figure 2.2 Diurnal Variation of PNC-NOx ratio (a) Arterial road; (b) Freeway. 
Figure 2.2 shows the diurnal variation of PNC-NOx ratio. The relative emission of PNC with respect to NOx remains fairly constant during the day at around 400-600 particles per ppb of NOx, except during the early morning, when this ratio is much higher. This suggests that in early morning, there are atmospheric processes that affect either one of the pollutants or affect both pollutants in different ways. At the freeway, the ratio varies between 200-400 particles per ppb of NOx, throughout the day.

\subsubsection{Effect of ambient temperature and wind speed on PNC-NOx ratio}

Linear regression analysis for several variables (i.e. temperature and wind Speed) was performed to investigate the impact of meteorological parameters on PNC-NOx ratio. Temperature was used to assess its importance on particle number concentration while wind speed was included as a proxy to illustrate the effect of ambient dilution on PNC-NOx ratio considering the unavailability of a direct measure of atmospheric stability.

Linear correlation parameters are used only to qualitatively express the correlation between ambient concentration of pollutants and meteorological factors i.e. wind speed and temperature. To investigate the relationship between the pollutants and meteorological parameters, hourly averages of PNC, NOx and PNC-NOx ratio were grouped within temperature and wind speed bins. 


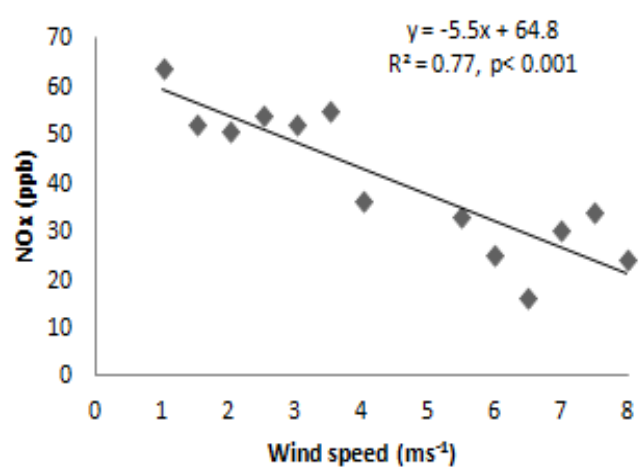

(a)

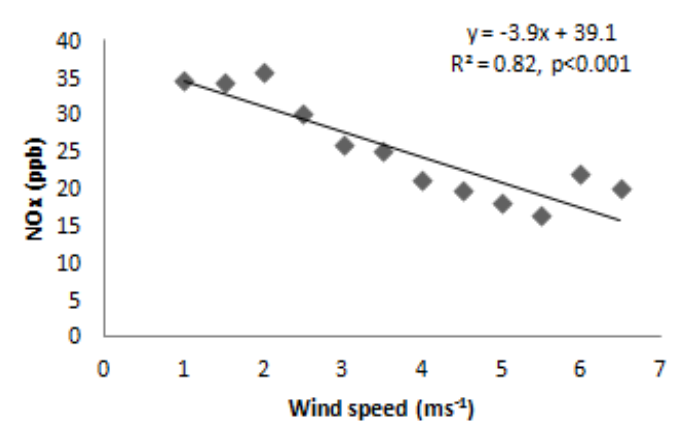

(c)

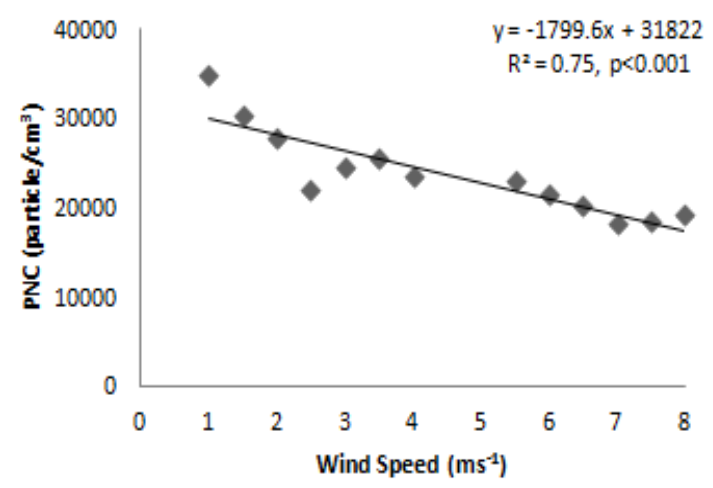

(b)

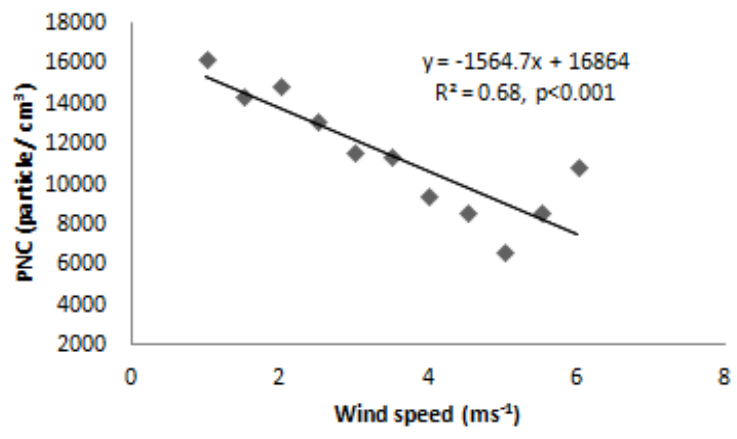

(d)

Figure 2.3 Scatter plot of PNC and NOx concentrations against wind speed; Arterial road $(a, b)$; Freeway $(c, d)$.

From figure 2.3, we can see that both PNC and NOx show a statistically significant negative relationship with wind speed. This demonstrates the diluting effect of wind speed on pollutants i.e. higher wind speed causes enhanced atmospheric mixing and thus lowers ambient concentration of pollutants. 


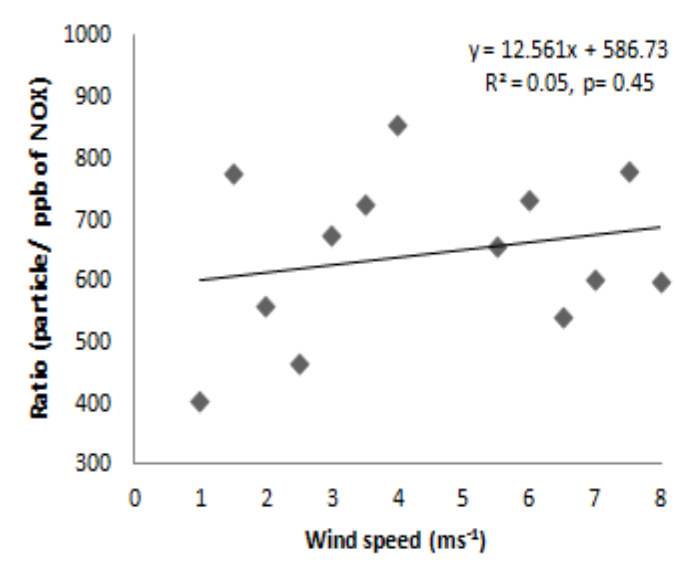

(a)

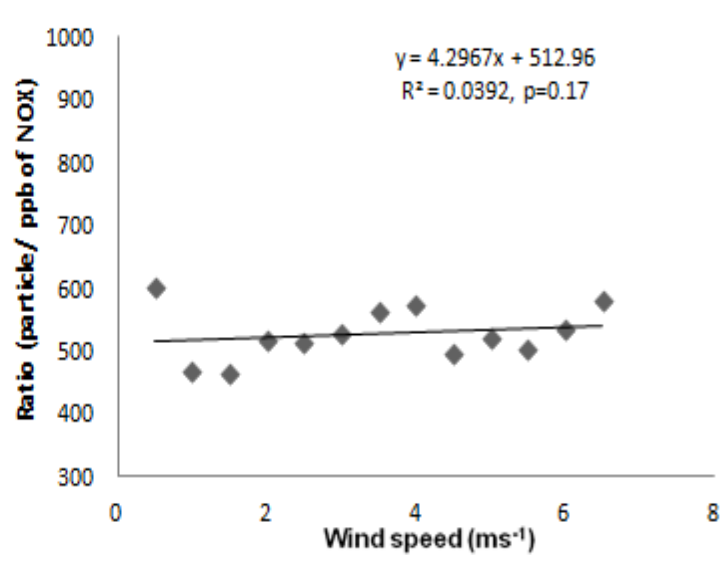

(b)

Figure 2.4 Scatter plot of PNC - NOx ratio against wind speed; (a) Arterial road; (b) Freeway.

When investigating the relationship between wind speed and PNC-NOx ratio, the linear relation is no longer statistically significant (Figure 2.4). This result was expected since when considering the PNC-NOx ratios, processes like traffic intensity and ambient dilution that affect both concentrations in similar ways are scaled out. This suggests that, coagulation and deposition can be neglected in a first estimate of PNC and the effect of wind speed on PNC near roads is mostly through dilution.

Figure 2.5 shows the relationship between the considered variable and ambient temperature. The measurements from the arterial road were conducted mostly during fall and winter and some in spring. The temperature during this time period ranges from $<5$ degree Celsius to 20 degree Celsius. Figure $2.5(\mathrm{a}, \mathrm{b})$ shows that NOx has no significant relationship with temperature. PNC shows negative correlation with ambient temperature with $p=0.03$. All the measurements from the freeway was conducted 
during summer and fall with temperature ranging from 10 degree Celsius to $>35$ degree Celsius. Both NOx and PNC measured along the freeway during this time period shows no correlation with ambient temperature (Figure 2.5; c, and d). Most of the variability of these two pollutants is explained by wind speed and therefore no or little variability is associated to ambient temperature.

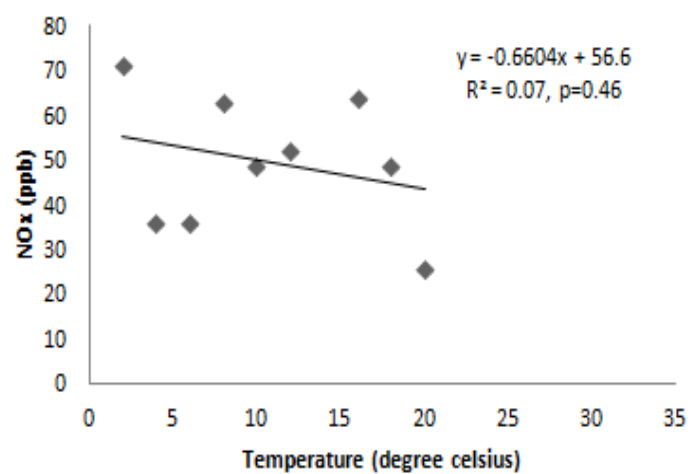

(a)

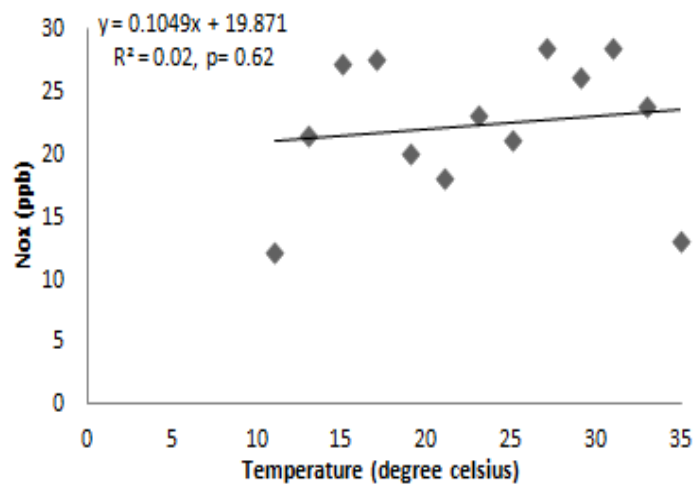

(c)

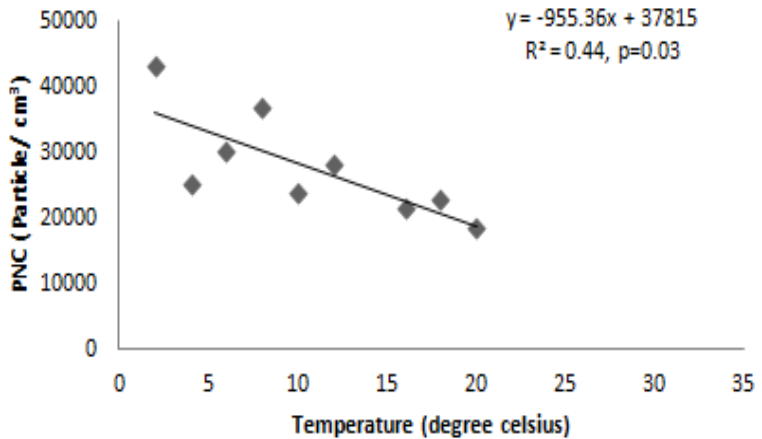

(b)

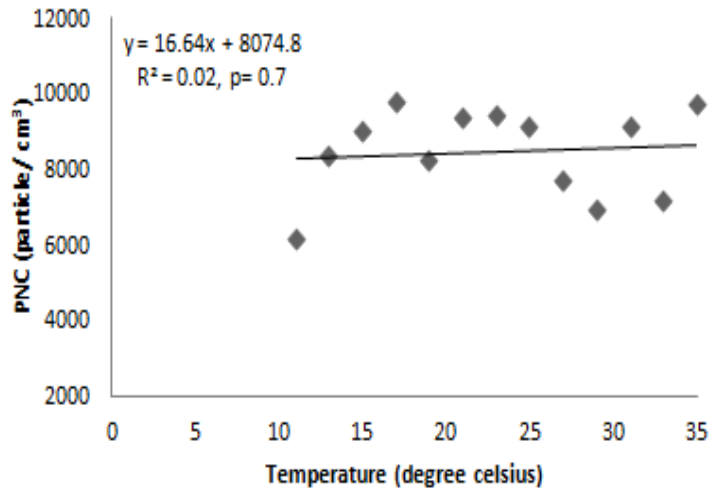

(d)

Figure 2.5 Scatter plot of PNC and NOx concentrations against ambient temperature; Arterial road (a, b); Freeway (c, d). 
However, when considering the relationship of PNC-NOx ratio with ambient temperature we can see PNC-NOx ratio correlates negatively with ambient temperature with $p<0.001$ for the arterial road (Figure 2.6). Such correlation was not observed for the measurements from the freeway which were collected at higher temperature ranges compared to the measurements taken at the arterial road at much lower temperature ranges.

Finally it can be concluded that NOx emission is temperature independent and can be used to reflect the effect of traffic intensity and meteorological dilution. Once the effect of traffic intensity and dilution is removed, the effect of temperature on PNCNOx ratio becomes important especially at very low temperatures ( $<10$ degree Celsius). So variation in PNC-NOx ratio can be attributed to the variation in PNC emission factors

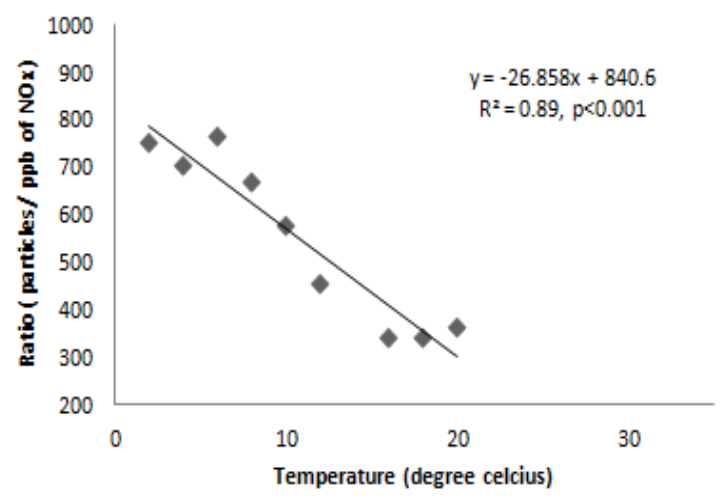

(a)

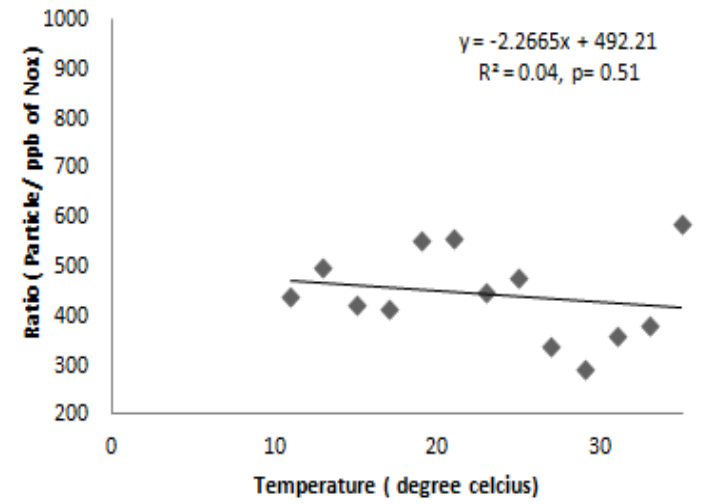

(b)

Figure 2.6 Scatter plot of PNC - NOx ratio against ambient temperature; (a) Arterial road; (b) Freeway. 
The key processes that affect the evolution of UFPs in an urban environment are nucleation, dilution, condensation, deposition and coagulation. However, coagulation and deposition are processes that are related to wind speed and vehicle induced turbulence rather than ambient temperature (Gidhagen et al, 2004)[91]. So the temperature dependent processes that can have an effect on PNC are nucleation of semi-volatile gases to form new particles and condensation of volatiles on existing particles. Both nucleation and condensation are competitive processes and depend on pre-existing particles in the atmosphere. In polluted urban environment with high preexisting surface area, formation of new particles through nucleation is less favorable than the condensation of low volatility vapors on existing particles (Charron and Harrison, 2003) [49].

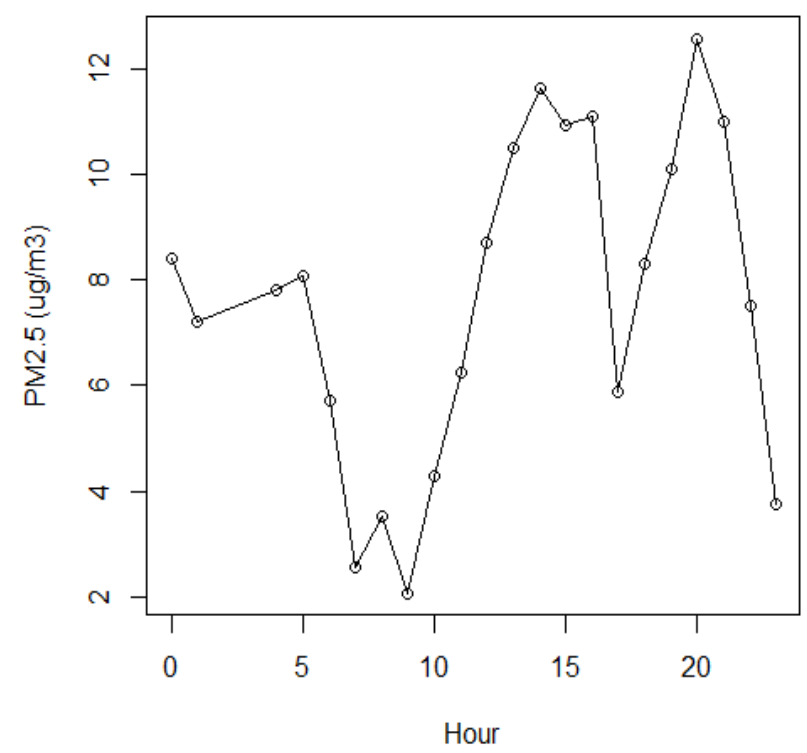

Figure 2.7 Diurnal $\mathrm{PM}_{2.5}$ at the arterial road 
Figure 2.7 shows the diurnal PM2.5 mass distribution at the arterial road. PM2.5 concentrations do not show a bi-modal distribution correlated with traffic. The morning PM2.5 peak has been found to occur slightly later than the traffic peak, at around 12:0014:00 LT, due to the secondary formation of fine particulate matter. On the other hand, in the arterial road, NOx and PNC show bi-modal diurnal distribution due to a combination of changing traffic volume and meteorology. The morning peak occurs at approximately 07:00-09:00 LT (Figure 2.1). This suggests that the morning PNC peak occurs when there is lower pre existing particles in the atmosphere.

So in this study, the high morning PNC/NOx ratio at the arterial road seem to be the result of new particle formation due to lower temperature and low concentration of exhaust gases in the morning air. The lack of pre-existing particles upon which condensation of volatiles can take place and higher super saturation due to lower temperature would favor new particle formation as hot tailpipe emissions mix with ambient air. Since the measurements at the freeway was conducted mostly in summer and Fall when the morning temperature never went below 10 degree Celsius, a temperature dependent PNC-NOx ratio was not observed. However a quantitative estimate of the temperature dependent increase in nucleation rate could not be determined with the available monitoring data.

To explore the variability of PNC and NOx relation at different ambient temperatures, the hourly values of these parameters were plotted at different 
temperature. From Figure 2.7 it can be seen that the relation changes during very cold temperatures compared to warmer conditions.

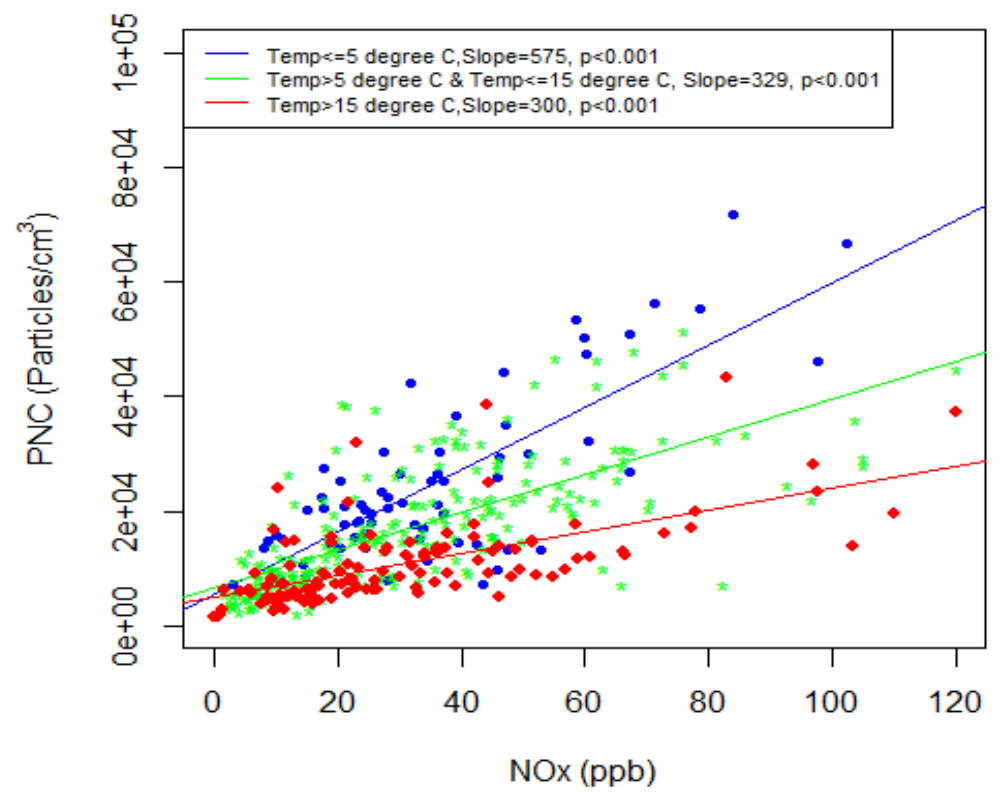

Figure 2.8 Relationship between hourly averages of PNC and NOx concentrations at different ambient air temperatures.

For the same NOx concentration, PNC levels are almost double for cold temperature interval (ambient temperature $<5$ degree $\mathrm{C}$ ) than warmer temperature interval (ambient temperature $>15$ degree $\mathrm{C}$ ).

\subsection{Conclusion}

Continuous measurement of UFP number concentrations and mass concentrations of $\mathrm{NO}, \mathrm{NO}_{2}$ and $\mathrm{PM}_{2.5}$ was conducted near an arterial road and freeway 
at different seasons and meteorological conditions and integrated with traffic count data. The correlation between PNC with various co-pollutants and traffic volume was investigated. PNC shows high correlation with nitrogen oxides and moderate to low correlation with traffic volume and $\mathrm{PM}_{2.5}$ respectively for both sites. This $\mathrm{PNC}-\mathrm{NO}_{\mathrm{x}}$ relationship prevailed on a shorter term (15 min), hourly, and throughout the day basis. Both PNC and NOx shows comparatively higher correlation with traffic during the morning period but gets lower during evening which can be attributed to the higher boundary layer and wind speeds. The variable meteorology in the evening affects both PNC and NOx concentrations in the same way and the correlation between NOx and PNC is maintained high both during morning and evening periods. Thus nitrogen oxides can be used as a proxy for traffic-related UFP number concentration reflecting the effect of both traffic intensity and meteorological dilution. This high correlation of PNC with NOx suggests the potential for predicting UFP exposure on the basis of NOx measurements. The PNC-NOx relation was explored under various meteorological conditions. Both PNC and NOx showed a statistically significant negative relationship with wind speed demonstrating the diluting effect of wind speed on pollutants. The relationship between wind speed and PNC-NOx ratio were no longer statistically significant when considering the PNC-NOx ratio since processes like traffic intensity and ambient dilution that affect both concentrations in similar ways are scaled out. Most of the variability of PNC and NOx concentrations is explained by wind speed and therefore little to no variability was found to be associated to ambient temperature. Once the 
effect of traffic intensity and dilution was removed, the effect of temperature on PNCNOx ratio became important. Such correlation was not observed for the measurements from the freeway which were collected at higher temperature ranges compared to the measurements taken at the arterial road at much lower temperature ranges.

The high morning PNC-NOx ratio at the arterial road can be attributed to the lower temperature prevailing in early mornings resulting in new particle formation due to lower temperature and low concentration of exhaust gases in the morning air favoring nucleation over condensation. For the same NOx concentration, PNC levels are almost double for cold temperature interval $(<5$ degree $\mathrm{C})$ than warmer temperature interval (>15 degree $\mathrm{C})$. This finding has important implication when calculating emission factors for UFP number concentrations. Thus it can be concluded that roadside concentration of ultrafine particles not only depends on traffic intensity but also on meteorological parameters affecting dilution or new particle formation. High concentrations of ultrafine particle number concentration close to a roadway is expected due to higher traffic intensity, as well as during low wind speed causing low dilution and low temperature conditions favoring new particle formation. 
CHAPTER 3: Determination and application of average emission factors for ultrafine particle number concentration.

\subsection{Introduction}

Individuals are exposed to elevated levels of ultrafine particle (UFP) number concentrations during their time spent near roadways. The link between exposure to UFPs and adverse health effects has highlighted the need to get detailed description of the emissions of UFP.

Emission factors are commonly used to characterize emission of certain pollutants from vehicles. Emission factors are defined as the average amount of a pollutant emitted per unit mass of fuel burned or distance travelled. Currently the existing regulations for particulate matter are mass based and consequently the existing data and emission factors are based on total mass emissions. Very few studies have been published on particle number emission factors from vehicles. For this reason, it is critical that particle number emissions be included in development of motor vehicle inventories and health impact assessments.

Conventionally, emission factors of pollutants are assessed based on dynamometer studies where concentrations in the gas stream of motor vehicles are measured that are placed on a dynamometer and then run through certain driving cycles. Although dynamometer studies are conducted for very well controlled conditions and establish uniform emission factors for regulatory purposes, they do not necessarily 
reflect the real on-road driving conditions that may vary depending on vehicle age, maintenance, driver's behavior etc. Real world emission factors from the actual car fleet under realistic driving conditions are essential to accurately assess exposure.

Exposure assessment for epidemiological studies requires modeling tools that can accurately account for pollutant variation. Dispersion models have been popularly used to reproduce pollutant gradient near roadways. Until recently, most of the efforts were focused on modeling the dispersion of gaseous pollutants. On the other hand very few attempts have been made to model dispersion of particle number concentration (PNC) near roadways. One possible constraint in modeling PNC is the lack of consistent experimental data on average emission factor for ultrafine particles from motor vehicles which is required as an input to these models.

So the objective of this chapter is to develop a less complex, indirect approach of determining real world emission factors for UFP number concentration based on monitoring data and using existing and easily available emission inventory for traffic related tracer gases. Roadside PNC exhibits high correlation with $\mathrm{NO}_{\mathrm{x}}$. Also it has been shown $\mathrm{NO}_{\mathrm{x}}$ and particles are diluted in the same way, and particle dynamic processes can be neglected in a first estimate as dilution is the absolute dominating process of fine particles near roads. Based on these findings, this study computes dilution on the basis of the emission factors available for nitrogen oxides (NOx) assumed to be well-known for numerous traffic situations which can be used to derive particle number emission factors. Also nitrogen oxides were used to distinguish high traffic and background 
exposure. The emission factors are suitable for fleet emissions under real-world traffic condition.

The calculated e emission factors were used in modeling the dispersion of trafficgenerated particles near roadways. Although the dispersion models treat PNC as inert gases and does not consider various transformation processes which is considered negligible closer to the roadway but may become significant as the particles travel away from source, the model can be useful in providing reference values of PNC gradients near roads.

\subsection{Theory and Methodology}

When considering dispersion of non-reactive pollutants, chemical transformation can be disregarded in a first approximate and the concentration of a pollutant, i at a particular point near roadway can be written as:

$\mathrm{C}_{\mathrm{i}}=\mathrm{F}_{\text {(met) }} * \mathrm{Q}_{\mathrm{i}}+\mathrm{C}_{\mathrm{i} \text {, background }}$

Here,

$C_{i}=$ Concentration of pollutant at a point near the street. (pollutant $/ \mathrm{m}^{3}$ );

$\mathrm{Q}=$ Emission from the average traffic volume (pollutant $/ \mathrm{m} / \mathrm{h}$ );

$\mathrm{C}_{i, \text { background }}=$ background contribution (pollutant $/ \mathrm{m}^{3}$ );

$\mathrm{F}_{\text {(met) }}=$ function describing the dispersion of pollutant $\left(\mathrm{hm}-{ }^{2}\right)$.

$F_{\text {(met) }}$ accounts for the losses due to dilution and deposition. 
Rearranging equation (1), emission from the street traffic can thus be calculated as:

$Q=\left(C_{i}-C_{i, \text { background }}\right) / F_{\text {(met) }}$

Consequently the average emission factors (pollutant/veh/ $\mathrm{m}$ ) can be calculated as:

So, $\mathrm{EF}_{\mathrm{i}}=\mathrm{Q} / \mathrm{N}_{\text {total }}$

Where,

$E F_{i}=$ Emission factor for pollutant $\mathrm{i}$ (pollutant/veh/ $\mathrm{m}$ )

$\mathrm{N}_{\text {total }}=$ Hourly traffic volume $\left(\right.$ Veh $\left.\mathrm{h}^{-1}\right)$

A direct calculation of particle number emission factor $\left(E_{P N C}\right)$ will require the calculation of the $F_{\text {(met) }}$ describing the dilution due to roadway mixing and atmospheric dispersion of tail-pipe emissions.

Two key concerns regarding the estimation of PNC emission factors in real world condition include the proper estimation of dilution rate from vehicle tailpipe to near roadway sampling site and the unavailability of continuous PNC measurements. Unlike particle mass, particle number is not conserved, and the numbers of particles produced by an engine may be significantly affected by the dilution conditions within the exhaust which controls the condensation processes (Shi and Harrison, 1999) [92]. When determining particle number emission rates there is a need to reflect real world dilution conditions. 
Currently there lacks detailed emission inventory for PNC. The existing dispersion models are designed to simulate the dispersion of inert gaseous pollutants. For this reason, this study computes dilution on the basis of the EFs of nitrogen oxides (NOx), $\mathrm{EF}_{\mathrm{NOx}}$ assumed to be well-known for numerous traffic situations, rather than focusing on particle number directly.

NOx is a co-pollutant with their major urban source in common with UFPs i.e. road vehicle emissions. NOx was selected as the traffic related tracer gas since the number concentration of particles was closely correlated to NOx ( $r=0.63)$.

Thus practical coefficient $D$ that accounts for both dispersion and traffic can be derived as:

Hourly Dilution Rate, $D=1 / F_{(m e t)}=Q_{\text {NOx }} /\left(C_{h}{ }^{\text {NOx }}-C_{\text {hbackground }}{ }^{\text {NOx }}\right)$

Or, $\mathrm{D}=\mathrm{EF}_{\mathrm{NOx}} * \mathrm{~N}_{\text {total }} /\left(\mathrm{C}_{\mathrm{h}}^{\mathrm{NOx}}-\mathrm{C}_{\mathrm{hbackground}}{ }^{\mathrm{NOx}}\right)$

Based on the assumption that NOx and particles are diluted in the same way, and particle dynamic processes can be neglected in a first estimate and dilution is the absolute dominating process of fine particles near roads (Zhang et al., 2004 [26]; Pohjola et al., 2003 [93]; Ketzel and Berkowicz, 2003 )[56], Particle number concentration emission factor, $\mathrm{EF}_{\mathrm{PNC}}$ is calculated as:

$Q_{P N C}=D^{*}\left(C_{P N C}-C_{P N C}\right.$, background $)$ 
Or, $\mathrm{EF}_{\mathrm{PNC}}=\mathrm{EF}_{\mathrm{NOx}} *\left(\mathrm{C}_{\mathrm{PNC}}-\mathrm{C}_{\mathrm{PNC} \text {, background }}\right) /\left(\mathrm{C}_{\mathrm{NOx}}-\mathrm{C}_{\mathrm{NOx}}\right.$, background $)$

Or, $\mathrm{EF}_{\mathrm{PNC}}=\mathrm{EF}_{\mathrm{NOx}} * \Delta \mathrm{C}_{\mathrm{PNC}} / \Delta \mathrm{C}_{\mathrm{NOx}}$

In this approach, if the emission factor of an existing and easily available tracer gas, i.e. NOx, $\mathrm{EF}_{\text {NOx }}$ is known, the emission ratio (ER) of roadside $\mathrm{PNC}$ and $\mathrm{NO}_{\mathrm{X}}, \mathrm{ER}_{\mathrm{PNC}-\mathrm{NOX}}$ can be converted to an emission factor for $\mathrm{PNC}, \mathrm{EF}_{\mathrm{PNC}}$. Describing the particle concentration as a ratio to an exhaust trace gas, e.g. NOx, the dilution effect will be minimized. Emission model, MOVES is used to estimate $\mathrm{EF}_{\mathrm{NOx}}$ and hence the dilution factor was determined. MOVES emission model is based on the measurement of pollutant emissions from dynamometer tests using a certain driving cycle. The EFs for UFPs are not available from the MOVES database. However, NOx EFs have been the subject of many investigations and reported in various literatures and thus are well known.

By relating to $\mathrm{EF}_{\mathrm{NOx}}$ to concurrent $\mathrm{NO}_{\mathrm{x}}$ and $\mathrm{PNC}$ measurements, Emission factor for PNC is calculated using equation 8. By normalizing PNC to a compound emitted from the same source, equation 8 is independent of calculations of dilution/meteorology.

\subsubsection{Calculation of emission ratio (ER)}

The emission ratio, ER is defined as the ratio of average roadside PNC to average roadside NOx concentrations. To ensure contribution of fresh traffic exhaust, the 
average of the difference of pollutant concentrations at high traffic condition and background condition was used.

$$
\text { Emission Ratio }=\frac{\text { Avg. PNC_High Traffic-Avg.PNC_background }}{\text { Avg conc.NOx_High Traffic }- \text { Avg.cono. NOx_background }}
$$

In theory background condition means the absence of any anthropogenic emission source of the pollutant. In practice, there are some limitations regarding the determination of background condition. In theory, pollutant concentrations at background conditions should be measured at the same time and location as the high traffic condition, but at the absence of traffic source. This is practically impossible. Also, if a second site is measured to serve as background, there is the potential of contribution from other local sources. Keeping these limitations in mind, NOx was used as a tracer to identify high-traffic and background conditions. NOx is a well-known traffic emitted pollutants and shows higher correlation with PNC than traffic volume.

Traffic volume was not used to define low and high traffic conditions as it has been demonstrated in previous chapter that the meteorological effects dominate and we get lower correlation of particle number concentration with traffic volume than it's correlation with traffic related gases, i.e nitrogen oxides. In this way, the background is considered to have lower concentration not only due to reduced traffic but also due to high dilution decreasing the concentration. Here the amount of traffic exhaust included in background calculations will affect both pollutants equally and the ration will not be affected. 
A majority of the NOx from traffic exhaust is emitted in the form of NO (Carslaw and Beevers, 2005) [94]. NO reacts with ozone to form $\mathrm{NO}_{2}$. This $\mathrm{NO}_{2}$ can be transformed back to NO by photochemical activity. Fresh emissions thereby contain high concentrations of $\mathrm{NO}$ and low concentrations of $\mathrm{NO}_{2}$. On the other hand, for aged air masses the $\mathrm{NO}$ to $\mathrm{NO}_{2}$ ratio will be lower. So high-traffic conditions can be selected based on High $\mathrm{NO}$ to $\mathrm{NO}_{2}$ ratio. Also, polluted air contains high $\mathrm{NO}_{\mathrm{x}}$ levels with high $\mathrm{NO}$ and $\mathrm{NO}_{2}$ concentrations and clear air will contain $\mathrm{NOx}$ levels with low $\mathrm{NO}$ and $\mathrm{NO} 2$ concentrations. Thus it can be assumed low $\mathrm{NO}_{x}$ concentrations may be used as an indicator of background conditions.

\subsubsection{R-LINE Dispersion Model}

R-LINE[95] is a research-grade line-source dispersion model developed by US EPA's Office of Research and Development and is used to calculate the dispersion of pollutants from each road link to each receptor. RLINE, designed to simulate primary, chemically inert pollutants, incorporates newly developed algorithms for predicting concentrations from on-road sources, e.g., tailpipe emissions from cars, buses, trucks and motorcycles. The model is based on a steady state Gaussian plume formulation and numerically integrates contribution from multiple point sources along the road link. The model automatically determines the number of points needed to represent each link. The model includes default dispersion parameters that are derived from field data and recent wind tunnel experiments for near road sources. Unlike other line source models, 
RLINE employs a wind meander algorithm that simulates dispersion in all directions during light and variable winds. What makes the model particularly suited for health and risk assessments in epidemiology studies is its ability to predict concentrations at receptors very close to roads.

The meteorological input needed for RLINE is obtained from the surface file output from AERMOD's met processor, AERMET (Cimorelli et al., 2005, [96]). AERMET processes surface characteristics (surface roughness, moisture and albedo), cloud cover, upper air temperature soundings, near surface wind speed, wind direction and temperature to compute the surface variables needed by AERMOD. The specific variables that are needed by RLINE include the surface friction velocity $\left(u^{*}\right)$, the convective velocity scale $\left(w^{*}\right)$, Monine Obukhov length $(L)$, the surface roughness height (zo), and the wind speed and direction at a reference height within the surface layer.

Meteorological data was acquired from National Weather Service (NWS) Integrated Surface Hourly Data (ISHD) format from Portland international airport (ftp://ftp.ncdc.noaa.gov/pub/data/noaa) which was determined to be representative of the study area. The upper air data was collected from National Ocean and Atmospheric Administration/Earth System Research Laboratory (NOAA/ESRL) Radiosonde database (RAOBS) for Salem, OR (http://esrl.noaa.gov/raobs/). AERMINUTE processes 1-minute wind data to generate hourly average winds for input to AERMET (http://www.epa.gov/scram001/metobsdata_procaccprogs.htm) .Minute wind data was 
downloaded from NOAA Automated Surface Observing System (ASOS) (ftp://ftp.ncdc.noaa.gov/pub/data/asos-onemin/6405-2016/).

Data for the year 2016 was processed by AERMET, which extracted data from data archives, completed quality assessment checks, merged surface, upper air and onsite data, and estimated boundary layer parameters.

\subsubsection{Site Description and measurements}

Continuous measurements of various traffic pollutants ( $N O, \mathrm{NO}_{2}, \mathrm{UFP}, \mathrm{PM}_{2.5}, \mathrm{CO}$ ) was collected from Oregon Department of Environmental Quality's near road air monitoring station located near interstate $5(1-5)$ at SW Bradbury court. An estimated on-road vehicle fleet from the I-5 freeway in Portland, Oregon, for 2010 includes $8.9 \%$ of the fleet made up of heavy duty diesel vehicles, similar to the U.S. average of $8 \%$ of vehicle miles traveled by trucks on urban freeways[84]. The peak hourly traffic volume is approximately 7000 vehicles and Average Annual Daily Traffic (AADT) is 151,500 vehicles.

The measurements were conducted from May, 2016 to September, 2016 when the ambient temperature ranging from 7-30 degree $\mathrm{C}$. By limiting the measurements of PNC to the period of May -September, a rather constant ambient temperature was achieved. 


\subsection{Results}

Table 3.1 shows the mean concentrations of pollutants at High-traffic and background conditions using nitrogen oxides as tracer gas. $20 \%$ of the data have been used to define each of the high traffic and background conditions.

Table 3.1 Average concentrations of pollutants at high-traffic (defined by high NO to NO2 ratio) and background conditions (defined by low NOx concentrations)

\begin{tabular}{ccccccc}
\hline & NO/NO2 & $\begin{array}{c}\text { NO } \\
\mathrm{ppb}\end{array}$ & $\begin{array}{c}\text { NO2 } \\
\mathrm{ppb}\end{array}$ & $\begin{array}{c}\text { NOx } \\
\mathrm{ppb}\end{array}$ & $\begin{array}{c}\text { PNC } \\
\text { Particle/cm3 }\end{array}$ & $\begin{array}{c}\text { CO } \\
\mathrm{ppb}\end{array}$ \\
\hline $\begin{array}{c}\text { High-Traffic } \\
\text { (High NO-NO }\end{array}$ & 2.1 & 37.33 & 15.52 & 52.89 & 12305 & 278.9 \\
$\begin{array}{c}\text { ratio) } \\
\text { Background } \\
\text { (Low NOx) }\end{array}$ & 0.4 & 2.27 & 7.20 & 9.72 & 3043 & 131 \\
\hline
\end{tabular}

A dataset formed with NO to NO2 ratio greater than the $80^{\text {th }}$ percentile is used to define high- traffic conditions and high traffic PNC and NOx concentrations are defined as the corresponding averages over the subset. Similarly, a dataset formed with NOx concentrations lower than the $20^{\text {th }}$ percentile is used to define background conditions and the background PNC and NOx concentrations are defined as the corresponding averages over that subset. Using nitrogen oxides as traffic related tracer gas, an emission ratio, ER of $214 \pm 17$ particles per ppb of NOx or (1.12 \pm 0.1$) \mathrm{E}+14$ particles per gram of NOx was found.

ER derived in this study was quite similar to the ERs found in other studies conducted in urban roadside settings (Table 3.2). Differences can be attributed to 
different particle sizes, season, fleet composition and speed variations.ER from this side compares well to the ER derived from light duty vehicles.

Table 3.2 On road emission ratios from studies conducted in urban roadside settings

\begin{tabular}{|c|c|c|c|c|c|}
\hline Site Description & Size range & $\begin{array}{c}\text { Temperature } \\
\text { (Degree } \\
\text { Celsius) }\end{array}$ & Fleet & $\begin{array}{c}\text { Emission Ratio } \\
\text { (Particle per } \\
\text { gram of NOX) }\end{array}$ & References \\
\hline $\begin{array}{c}\text { California,USA } \\
\text { Tunnel }\end{array}$ & $>10 \mathrm{~nm}$ & Summer & LDV & $0.5 \mathrm{E}+14$ & $\begin{array}{c}\text { Kirchstetter et } \\
\text { al. (1999) [97] }\end{array}$ \\
\cline { 2 - 5 } & $>10 \mathrm{~nm}$ & Summer & HDV & $1.5 \mathrm{E}+14$ & Noble et al. \\
\hline $\begin{array}{c}\text { El Paso, USA } \\
\text { Street }\end{array}$ & $20-100$ & $-2-22$ & n.a & $0.8 \mathrm{E}+14$ & $\begin{array}{c}\text { Kittelson et al. } \\
\text { 2004 [99] }\end{array}$ \\
\hline $\begin{array}{c}\text { Minnesota, USA } \\
\text { Highway }\end{array}$ & $>3$ & $1-13$ & $\begin{array}{c}\text { Gasoline } \\
\text { Dominat } \\
\text { ed fleet }\end{array}$ & $4 \mathrm{E}+14$ & $\begin{array}{c}\text { JanhÄll et al. } \\
\text { 2005 [100] }\end{array}$ \\
\hline $\begin{array}{c}\text { Sweden } \\
\text { Urban roadside }\end{array}$ & $10-100 \mathrm{~nm}$ & $8-14$ & fleet & $0.7 \mathrm{E}+14$ & $\begin{array}{c}\text { Jamriska, M., \& } \\
\text { Morawska, L. } \\
\text { (2001) [101] }\end{array}$ \\
\hline $\begin{array}{c}\text { Australia, } \\
\text { Roadside }\end{array}$ & $5-900 \mathrm{~nm}$ & $\sim 25$ & fleet & $1.25 \mathrm{E}+14$ & $\begin{array}{c}\text { Gramotnev et } \\
\text { al (2003) [102] }\end{array}$ \\
\hline $\begin{array}{c}\text { Australia, } \\
\text { Highway }\end{array}$ & $15-900 \mathrm{~nm}$ & $30-35$ & fleet & $2 \mathrm{E}+14$ & This study \\
\hline Portland, OR, USA & $20-1000 \mathrm{~nm}$ & $7-30$ & fleet & $1.12 \mathrm{E}+14$ & \\
\hline
\end{tabular}

The ER reported by Kittelson et al. 2004 [99] from a study conducted on Minnesota highway with gasoline dominated fleet was significantly higher. This study was conducted at lower ambient temperature and high speed and load conditions, such as freeway cruise and hard acceleration. Graskow et al., 1998 [103] ,CONCAWE, 1998 [104], McAughey et al., 1996 [105] conducted laboratory studies and showed that emission of UFPs from gasoline engines are load and speed dependent and produce 
UFP emission as high as diesel vehicles under high speed and load conditions. Despite some differences in reported ERs due to different particle sizes, season, fleet composition and speed variations, it is important to note that there is reasonable agreement in emission ratios between vehicle fleets in different locations in the world.

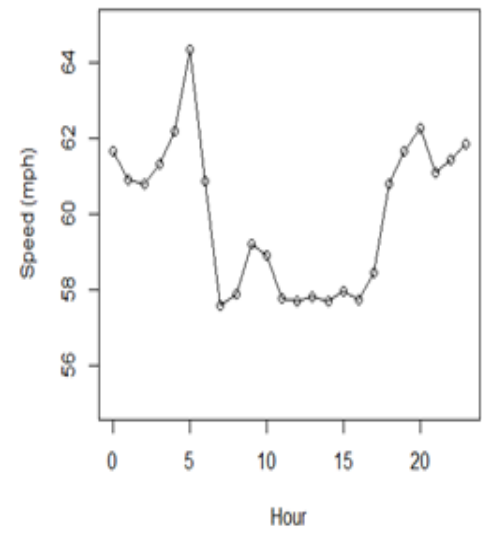

(a)

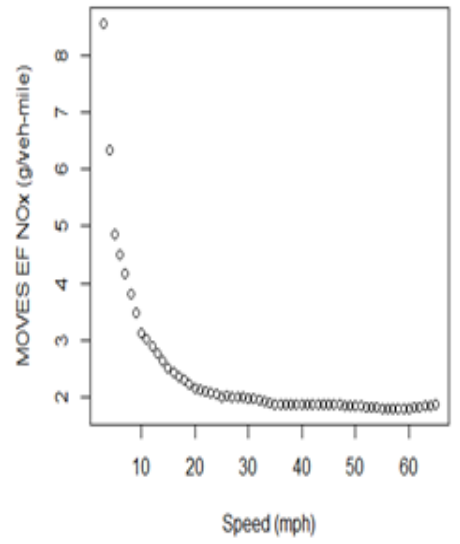

(b)

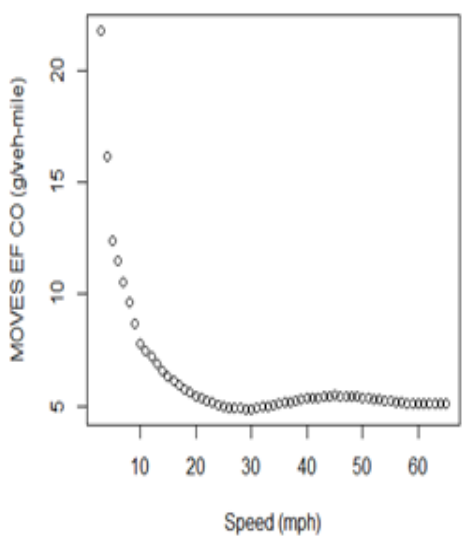

(c)

Figure 3.1 (a) Average hourly speed of traffic on I -5 collected from PORTAL; (b) Speed based MOVES emission factor for NOX; (c) Speed based MOVES emission factor for CO.

The emission ratio of roadside $\mathrm{PNC}$ and $\mathrm{NO}_{\mathrm{x}}, \mathrm{ER}_{\text {PNC-NOx }}$ is converted to an emission factor for PNC using equation 8. The $\mathrm{EF}_{\mathrm{NOx}}$ used to convert $\mathrm{ER}_{\mathrm{PNC}-\mathrm{NOx}}$ to $\mathrm{EF}_{\mathrm{PNC}}$ was based on MOVES emission model. Speed-based NOx emission factors for freeways ranging from 3-65 $\mathrm{mph}$ for summer time conditions were provided by modelers at Metro (Portland's regional government) based on the 2014 MOVES outputs produced for Metro's 2014 Regional Transportation Plan (RTP) [Metro. 2014 Regional 
Transportation Plan.]. Composite emission factors accounting for characteristics of both Oregon and Washington fleets were used.

The hourly average speed data was accessed from the Portland Oregon Regional Transportation Archive Listing (PORTAL). The average speed of traffic on I-5 stays fairly constant during the day (from $7 \mathrm{am}$ to $7 \mathrm{pm}$ ) ranging from 57 to $60 \mathrm{mph}$. During nights and early morning slightly higher average speed of around $65 \mathrm{mph}$ is observed. (Figure 3.1 a).

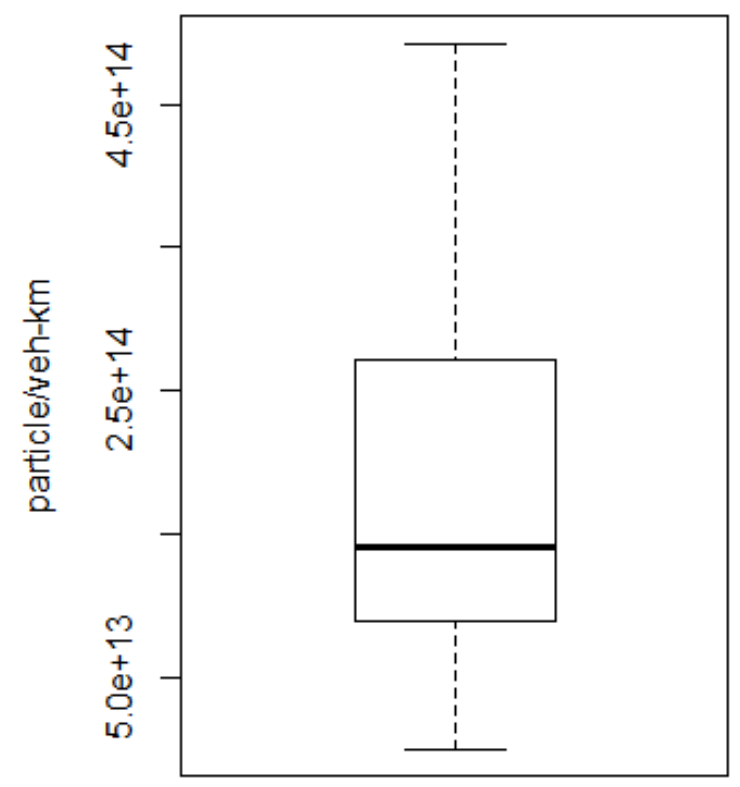

Figure 3.2 Average PNC emission factor derived using NOx emission factors. MOVES emission factor for each hour of the high traffic conditions were selected based on the median speed of traffic in that hour. MOVES EF for NOx for speed range of 
55-65 mph were found 1.81-1.87g/veh-mile (Figure 3.1 b). Using equation 8 , an average of (1.82 \pm 0.48$) \mathrm{E}+14$ particle/vehicle-km was found (Figure 3.2, Table 3.3).

Table 3.3 Summary of Particle Number emission factors calculated using NOx emission factors

\begin{tabular}{|c|c|}
\hline Parameter & EF $_{\text {PNC }}$ (particle/veh-km) \\
\hline Mean \pm standard error & $(1.82 \pm 0.48) \mathrm{E}+14$ \\
\hline Median & $1.41 \mathrm{E}+14$ \\
\hline $5^{\text {th }}$ Percentile & $2.11 \mathrm{E}+13$ \\
\hline $95^{\text {th }}$ percentile & $3.84 \mathrm{E}+14$ \\
\hline
\end{tabular}

The average emission factor for PNC calculated by dynamometer test reported in various literatures is given in table 3.4. The range of EFs from dynamometer test lie between $10^{\wedge} 11$ particle/veh-km to $10^{\wedge} 14$ particle/veh-km to for gasoline powered engines and between $10^{\wedge} 13$ particle/veh-km to to $10^{\wedge} 14$ particle/veh-km for diesel powered engines.

The EF from diesel powered engine is higher than the EF of gasoline powered engine. Also the reported EFs show large variation. The reason for this variation can be attributed to the differences in vehicle conditions, testing procedure and combustion technologies etc. Although the calculated emission factors based on on-road PNC and NOx measurements are comparable to the EFs reported by the dynamometer tests, dynamometer studies may be under-predicting the emissions present in real world situations. The reason for this under prediction could be attributed to the fact that only a small number of vehicles are involved in dynamometer test which may not be fully 
representative of traffic fleet in real world conditions. Also increase of emissions during acceleration and the presence of high emitters in real world which are not included in dynamometer tests might result in lower EFs from dynamometer tests.

Table 3.4 Particle Number emission factor from dynamometer tests

\begin{tabular}{|c|c|c|}
\hline \multicolumn{1}{|c|}{ Study } & \multicolumn{2}{c|}{$\begin{array}{c}\text { Emission factor } \\
\text { (particle/veh-km) }\end{array}$} \\
\hline & Gasoline & Diesel \\
\hline Ristovski et al., 1998 [106] & $1.74 \times 10^{11}$ & $6.56 \times 10^{13}$ \\
\hline Graskow et al., 1998 [103] & $(0.38-1.01) \times 10^{12}$ & n.a \\
\hline McAughey et al., 1996 [105] & $(1.13-1.14) \times 10^{14}$ & $(1.17-1.85) \times 10^{14}$ \\
\hline Farnlung et al. 2001[107] & $1.7 \mathrm{E}+13$ & $1.0 \mathrm{E}+14$ \\
\hline Morawska et al. 1998[108] & n.a. & $1.57 \mathrm{E}+14$ \\
\hline CONCAWE, 1998[104] & $4.76 \times 10^{13}$ & $1.42 \times 10^{14}$ \\
\hline
\end{tabular}

$\mathrm{CO}$ is another traffic emitted air pollutants. In this study we also tested $\mathrm{CO}$ as an alternative to using NOx as a traffic indicator. Also we used $\mathrm{CO}$ emission factors from MOVES (Figure $3.1 \mathrm{c}$ ) to calculate $\mathrm{EF}_{\mathrm{PNC}}$.

Table 3.5 shows the mean concentrations of pollutants at High-traffic and background conditions using $\mathrm{CO}$ as tracer gas. When using $\mathrm{CO}$ as a tracer gas, the PNC and $\mathrm{NO}_{\mathrm{x}}$ corresponding to High-traffic conditions is lower than the concentrations estimated using $\mathrm{NO}$ to $\mathrm{NO}_{2}$ ratio as an indicator to high traffic. 
Table 3.5 Average concentrations for High- traffic and background conditions defined by CO concentrations

\begin{tabular}{ccccccc}
\hline & $\begin{array}{c}\mathrm{NO} \\
\mathrm{NO}_{2}\end{array}$ & $\begin{array}{c}\mathrm{NO} \\
\mathrm{ppb}\end{array}$ & $\begin{array}{c}\mathrm{NO}_{2} \\
\mathrm{ppb}\end{array}$ & $\begin{array}{c}\mathrm{NOx} \\
\mathrm{ppb}\end{array}$ & $\begin{array}{c}\mathrm{PNC} \\
\times 10^{3} \mathrm{~cm}^{-3}\end{array}$ & $\begin{array}{c}\mathrm{CO} \\
\mathrm{ppb}\end{array}$ \\
\hline $\begin{array}{c}\text { High traffic } \\
\text { (High CO Conc.) }\end{array}$ & 1.5 & 27.4 & 17.86 & 45.5 & 10762 & 357.8 \\
$\begin{array}{c}\text { Background } \\
\text { (Low CO Conc.) }\end{array}$ & 0.6 & 6.9 & 10 & 17 & 5245 & 34.5 \\
\hline
\end{tabular}

Table 3.6 Emission ratios calculated using either NOx or CO to identify High-traffic and background conditions

\begin{tabular}{|c|c|c|}
\hline & Nitrogen Oxides as Indicator & CO as Indicator \\
\hline \multicolumn{3}{|c|}{ Emission Ratio (mean) } \\
\hline $\begin{array}{c}\text { ER }_{\text {PNC-NOx }} \\
\text { (Particle per ppb of NOx) }\end{array}$ & 214 & 194 \\
\hline $\begin{array}{c}\text { ER }_{\text {PNC-CO }} \\
\text { (Particle per ppb of CO) }\end{array}$ & 61.5 & 16 \\
\hline \multicolumn{3}{|c|}{ Emission Factor (mean \pm Standard Error) } \\
\hline $\begin{array}{l}\text { ER }_{\text {PNC-NOX }} \text { X EF } \\
\text { (Particle/veh-km) }\end{array}$ & $(1.82 \pm 0.48) E+14$ & $(1.89 \pm 0.60) E+14$ \\
\hline $\begin{array}{c}\text { ER }_{\text {PNC-Co }} \times E_{\text {CO }} \\
\text { (Particle/veh-km) }\end{array}$ & $(2.38 \pm 0.22) E+14$ & $(6.2 \pm 0.79) E+13$ \\
\hline
\end{tabular}

Table 3.6 shows emission ratios calculated using either NOx or CO as tracer gas to identify high traffic and background conditions. We can see that the ERs calculated as Particles per ppb of NOx is quite similar in both tracer methods, i.e. 214 Particles ppb of NOx using Nitrogen oxides as tracer gas and 194 Particle per ppb of NOX, using CO as tracer gas. By relating these ERs to emission factors for NOx, PNC emission factors were 
derived as (1.82 \pm 0.48$) \mathrm{E}+14$ Particle/veh-km and (1.89 \pm 0.60$) \mathrm{E}+14$ Particle/veh-km respectively.

The ERs calculated as Particles per ppb of CO is significantly different using the two tracer methods. Using $\mathrm{CO}$ as tracer gas the emission ratio is underestimated than the ER calculated using Nitrogen oxides as tracer gas. CO behaves differently in the atmosphere compared to nitrogen oxides. Ratio of $\mathrm{CO}$ and NOx varies among different combustion processes. CO originates from both gasoline and diesel vehicles, whereas diesel vehicles have been mostly connected to the emission of NOx and particle emissions, with particle diameter above $7 \mathrm{~nm}$ (Colvile et al., 2001[109]; Harris and Maricq, 2001 [110]; 2001; Zielinska et al., 2004 [111]). Also CO has a much longer lifetime than NOx. The lifetime of $\mathrm{CO}$ is long enough that there exists a global background concentration. This vary systematically with season because of photochemical processing [112].

When using $\mathrm{CO}$ as indicator of high traffic condition, the PNC and $\mathrm{NO}_{\mathrm{x}}$ corresponding to high traffic conditions is lower than the concentrations estimated using $\mathrm{NO}$ to $\mathrm{NO}_{2}$ ratio as an indicator to high traffic. Since both PNC and $\mathrm{NO}_{\mathrm{x}}$ are affected the same way when using $\mathrm{CO}$ as tracer gas, the ratio of PNC to $\mathrm{NO}_{x}, \mathrm{EF}_{\mathrm{PNC}-\mathrm{NO}}$ remains unchanged. When using NOX to define background, the corresponding $\mathrm{CO}$ is much higher than the background calculated using lower quintile of $\mathrm{CO}$. For this reason, the $\mathrm{EF}_{\mathrm{PNC}-\mathrm{CO}}$ is much lower when $\mathrm{CO}$ was used to define the background. Also the poor correlation between 
$\mathrm{CO}$ and NOx or particle compounds, $r<0.3$, might be due to the low CO concentrations in traffic emissions compared to ambient background CO.

The calculated emission factor and R-Line dispersion model was tested in predicting near-road particle number concentrations. So far, dispersion models have been used to simulate the dispersion of gaseous pollutants. One of the difficulties regarding the application of dispersion models to simulate the propagation of ultrafine particles from busy roads is the absence of consistent experimental data on particle number emission factors from motor vehicles to be used as an input of these models.

We used R-line dispersion model designed to simulate the dispersion of nonreactive inert gases from vehicular emissions near roadway to simulate the dispersion of Particle number concentrations using an emission factor derived by the above described procedure.

We hypothesize that particle dynamic processes can be neglected in a first estimate since it is verified that dilution is the absolute dominating process of fine particles near roads. Using an average emission factor of $1.82 \mathrm{E}+14$, and meteorological input from AERMOD and using hourly concurrent traffic volume from PORTAL, R-LINE dispersion model was run to simulate PNC at a distance of $45 \mathrm{~m}$ from the road, where the air measurement site was located. 
An estimated background of 3000 particle/ cm3 was added to modeled concentrations so that they can be compared to actual measurements. . When paired in space and time, $84.33 \%$ of all points $(n=252)$ fell within the factor of two envelope.

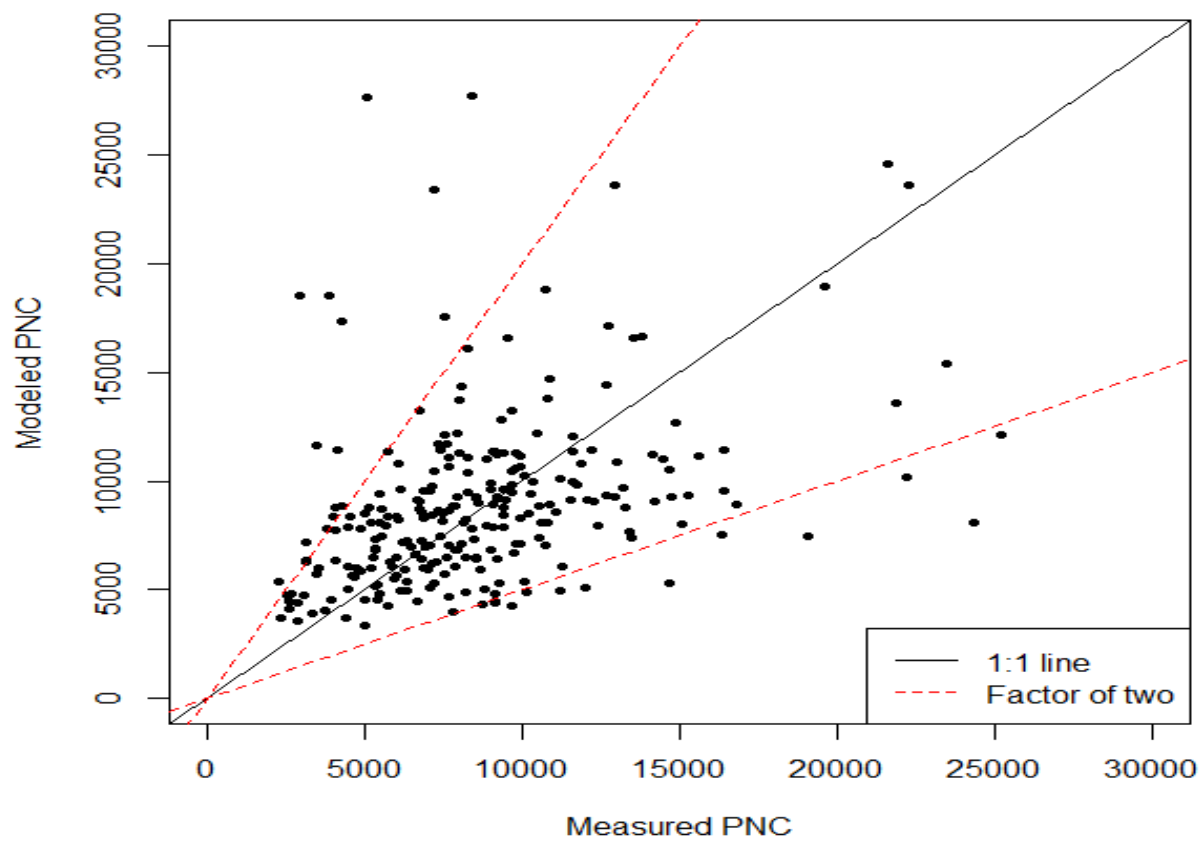

Figure 3.3 Modeled vs. Measured particle number concentrations.

A linear regression model was performed between the modeled and measured PNC. The calculated $R^{2}$ value was approximately $23 \%$. This result suggests that the $R$ Line dispersion model can account for some parameters affecting PNC but a lot of the variability is unexplained. $\mathrm{R}$-line computes dispersion of a pollutants accounting for large meteorological conditions such as wind speed and direction but it doesn't include vehicle induced turbulence, sinks and transformation processes that might affect 
dispersion of particle number concentrations. Also uncertainty of the dispersion models to accurately produce the dispersion of the pollutants might affect the modeled results.

Despite a lower $R^{2}$ value, the results are still good based of the factor of two analysis and indicate that although ultrafine particles undergo various physical and chemical processes resulting in rapid transformation of particle modes, it may be expected that the total number concentration near a busy road can be approximately described and predicted by means of the Gaussian plume model.

Finally, the findings from this study are applied on a larger scale to produce a simplified map of PNC gradients from traffic sources from major roads of Portland, OR (Figure 3.4). Specific emissions for each road link were calculated by combining national database information on traffic volume and fleet mix with emissions factors from EPA's MOVES -2010b modeling system. Using average summertime wind direction and Neutral atmospheric stability, dispersion of NOx from major roadway were modeled using Gaussian plume formulation. The modeled NOx concentrations were scaled using PNC-NOx ratio, found to be more or less constant for a variety of traffic conditions, to produce a map of particle number concentrations from traffic sources. For winter time, at low temperatures this ratio is expected to rise higher and hence higher than the predicted PNC is expected. 


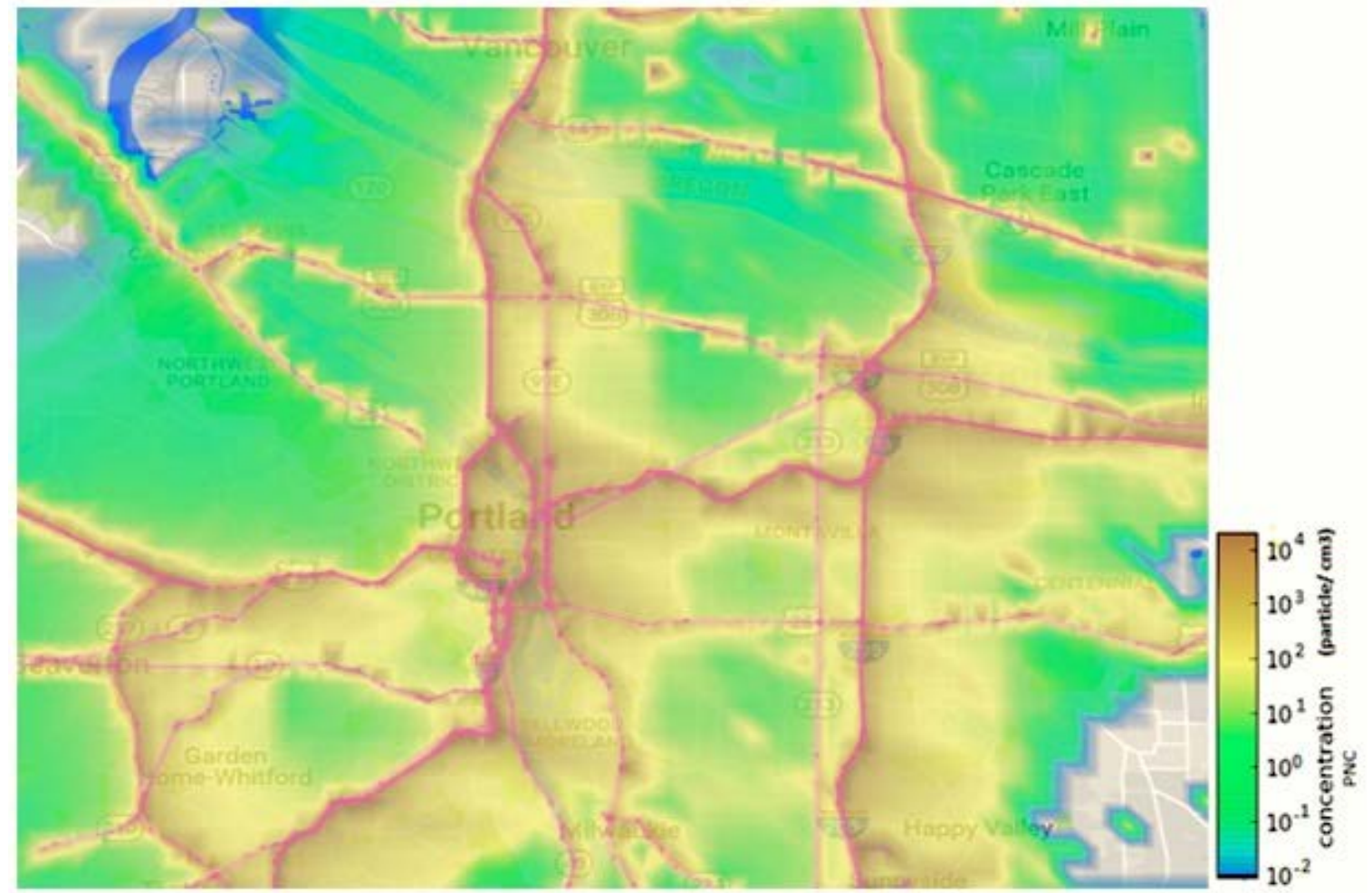

Figure 3.4 Average summertime hourly concentrations of PNC from traffic sources for Portland, OR

Although the produced map does not offer high spatial resolution data and treats ultrafine particles as inert gases without taking into account of various transformation processes, it can be used as an effective illustration of high particle number concentrations expected near roadways and to provide some reference values for estimating exposure to UFP in near road environment.

\subsection{Conclusion}

A simplified approach of calculating particle number emission factor was developed using existing and easily available emission inventory for traffic related tracer 
gases. Using emission factors from MOVES emission model, the emission ratio of particle number to co-pollutants was converted to develop particle number emission factors. NOx was selected as the traffic related tracer gas since the number concentration of particles was closely correlated to NOx and NOx emission factors are available for a variety of traffic situations. It was assumed that NOx and particles are diluted in the same way, and particle dynamic processes can be neglected in a first estimate and dilution is the absolute dominating process of fine particles near roads. Thus, by describing the particle number concentration as a ratio to an exhaust trace gas, NOx, the dilution effect was minimized. To ensure contribution of fresh traffic exhaust, the average of the difference of pollutant concentrations at high traffic condition and background condition was used to calculate $\mathrm{PNC}-\mathrm{NO}_{\mathrm{x}}$ ratio. The average high-traffic and background concentration of pollutants was calculated using both nitrogen oxides and $\mathrm{CO}$ and compared. It was found that, by defining high-traffic condition by high NO to $\mathrm{NO}_{2}$ ratio and background by low NOX concentration, it was possible to extract concentrations that are only affected by traffic emissions. Using nitrogen oxides to define background and high-traffic conditions and MOVES emission factor for NOX to convert corresponding PNC-NOX ratio, an average emission factor of (1.82 \pm 0.17$) E+14$ particle/ veh-km was obtained. This emission factor is suitable for summer time conditions when the ambient temperature is approximately $>5$ degree C. During cold winter mornings favoring new particle formation, the PNC-NOX ratio is expected to be twice as high leading to higher emission factors for PNC. Also this method provided 
emission factors for the average traffic fleet on 1-5. When applied to different roadways, this method may lead to an estimate of emission factors for different type of vehicles. When compared to existing particle number emission factors derived from dynamometer tests, it was found that although there exits reasonable agreement between the calculated real world particle number emission factor and emission factors from dynamometer tests, dynamometer studies may be under-predicting the emissions present in real world situations. This under prediction may be attributed to the inability of dynamometer tests to accurately represent real world traffic characteristics. Finally, the calculated emission factor and R-Line dispersion model was tested in predicting near-road particle number concentrations. Although only $23 \%$ of the variability in PNC was explained by the dispersion model, $84.33 \%$ of the measurements fell within the factor of two envelope. This suggests that there is potential to effectively use these models and thus warrants more in-depth analysis. 
CHAPTER 4: Implications and Future Directions

While scientific information on particle mass has been the subject of much research, there is a severe lack of representative sets of roadside measurements of particle number concentrations (PNCs) that could be used in epidemiological studies. Modeling efforts to predict ultrafine particles (UFPs) have also been limited due to the scarcity of reliable information on emissions, lack of monitoring data and limited understanding of complex processes affecting PNC near sources.

In this study, long term continuous measurements from roadside stations were used to explore the relationship between roadside UFP number concentrations with various co-pollutants that helped identify proxy-indicators to provide reference values for estimating UFP concentrations. Thus using existing emission inventory of regulated gaseous pollutants, a simplified method of determining emission factors for PNC was developed and its capability to predict PNC using dispersion models was evaluated. The dispersion models can be used for simple evaluation of particle concentration near major roadways for environmental and urban planning purposes and to assess expected impact of UFP pollution on population living near roadways exposed to elevated concentrations.

The simplified approach of calculating emission factors was applied to derive emission factors for the average traffic fleet on $1-5$. In the presence of fleet composition 
data, it is possible to apply the same procedure to come up with emission factors for different vehicle types, i.e. Light-duty and Heavy-duty vehicles.

In this study, the number concentration of particles within the size range of 20 to $1000 \mathrm{~nm}$ was measured without knowledge of the size distribution. The correlation between NOx and UFP depend on the particle size. For particles bigger than $200 \mathrm{~nm}$ and particles smaller than $30 \mathrm{~nm}$, weaker correlation of PNC with NOx is expected (Ketzel et al., 2003[56]). Also difference in measurement settings can affect correlation between PNC and NOx. NO is expected to be a better tracer for UFP for short lived exhaust emissions in the $20-30 \mathrm{~nm}$ range, close to a major highways. On the other hand, $\mathrm{NO}_{2}$ correlation might be higher for particles in the $30-100 \mathrm{~m}$ and greater than $100 \mathrm{~nm}$ size range and be better tracer for regional emissions and for small streets with lower traffic densities with longer period to favor formation of $\mathrm{NO}_{2}$. Thus correlation of nitrogen oxides with PNC at different size bins should be investigated to gain better knowledge about the emission sources and size fractions of emitted particles and develop size resolved emission factors for PNC. This has important implications in health studies since different particle sizes are associated with different health outcomes.

There are a number of rapid evolutionary processes affecting UFP number and size distribution near source. In this study, these dynamic processes have been neglected in a first approximate as dilution is the absolute dominating process near roads. Thus the measured PNC was considered to be mostly primary emissions. But under certain atmospheric conditions and geographic situation, the effect of these 
processes can be significant on PNC. A more detailed study, reflecting the effect of meteorology especially temperature and relative humidly on various atmospheric processes favoring secondary particle formation through Nucleation and Condensation, should be studied more in depth.

Properly taking into account of these discussed factors, a detailed emission inventory characterizing ultrafine particle emission form sources and their fate into the atmosphere can be assessed. This would result in improved estimation of particle concentration and thereby inform formulation of effective regulations and control strategies. 
References:

[1] G. M. Rowangould, "A census of the US near-roadway population: Public health and environmental justice considerations," Transp. Res. Part Transp. Environ., vol. 25, pp. 59-67, Dec. 2013.

[2] C. A. Pope and D. W. Dockery, "Health Effects of Fine Particulate Air Pollution: Lines that Connect," J. Air Waste Manag. Assoc., vol. 56, no. 6, pp. 709-742, Jun. 2006.

[3] W. H. O. R. O. for Europe, "Health aspects of air pollution : results from the WHO project 'Systematic review of health aspects of air pollution in Europe,'” 2004.

[4] C. C. Daigle et al., "Ultrafine Particle Deposition in Humans During Rest and Exercise," Inhal. Toxicol., vol. 15, no. 6, pp. 539-552, Jan. 2003.

[5] G. Oberdörster and M. J. Utell, "Ultrafine particles in the urban air: to the respiratory tract--and beyond?," Environ. Health Perspect., vol. 110, no. 8, pp. A440441, Aug. 2002.

[6] G. Oberdörster, E. Oberdörster, and J. Oberdörster, "Nanotoxicology: an emerging discipline evolving from studies of ultrafine particles," Environ. Health Perspect., vol. 113, no. 7, pp. 823-839, Jul. 2005.

[7] L. Morawska, N. D. Bofinger, L. Kocis, and A. Nwankwoala, "Submicrometer and Supermicrometer Particles from Diesel Vehicle Emissions," Environ. Sci. Technol., vol. 32, no. 14, pp. 2033-2042, Jul. 1998.

[8] C. O. Stanier, A. Y. Khlystov, and S. N. Pandis, "Ambient aerosol size distributions and number concentrations measured during the Pittsburgh Air Quality Study (PAQS)," Atmos. Environ., vol. 38, no. 20, pp. 3275-3284, Jun. 2004.

[9] J. H. Seinfeld and S. N. Pandis, Atmospheric Chemistry and Physics: From Air Pollution to Climate Change, 2 edition. Hoboken, N.J: Wiley-Interscience, 2006. 
[10] L. Morawska, Z. Ristovski, E. R. Jayaratne, D. U. Keogh, and X. Ling, "Ambient nano and ultrafine particles from motor vehicle emissions: Characteristics, ambient processing and implications on human exposure," Atmos. Environ., vol. 42, no. 35, pp. 8113-8138, Nov. 2008.

[11] P. A. Solomon and P. K. Hopke, "A Special Issue of JA\&WMA Supporting Key Scientific and Policy- and Health-Relevant Findings from EPA's Particulate Matter Supersites Program and Related Studies: An Integration and Synthesis of Results," J. Air Waste Manag. Assoc., vol. 58, no. 2, pp. 137-139, Feb. 2008.

[12] P. Kumar et al., "Ultrafine particles in cities," Environ. Int., vol. 66, pp. 1-10, May 2014.

[13] J. Pey, X. Querol, A. Alastuey, S. Rodríguez, J. P. Putaud, and R. Van Dingenen, "Source apportionment of urban fine and ultra-fine particle number concentration in a Western Mediterranean city," Atmos. Environ., vol. 43, no. 29, pp. 4407-4415, Sep. 2009.

[14] F. Costabile et al., "Spatio-temporal variability and principal components of the particle number size distribution in an urban atmosphere," Atmos Chem Phys, vol. 9, no. 9, pp. 3163-3195, May 2009.

[15] R. M. Harrison, D. C. S. Beddows, and M. Dall'Osto, "PMF Analysis of Wide-Range Particle Size Spectra Collected on a Major Highway," Environ. Sci. Technol., vol. 45, no. 13, pp. 5522-5528, Jul. 2011.

[16] M. Dall'Osto et al., "Urban aerosol size distributions over the Mediterranean city of Barcelona, NE Spain," Atmos Chem Phys, vol. 12, no. 22, pp. 10693-10707, Nov. 2012.

[17] T. Hussein et al., "Fingerprints of the urban particle number size distribution in Helsinki, Finland: local versus regional characteristics," Boreal Environ. Res., vol. 19, no. 1, pp. 1-21, Feb. 2014. 
[18] Z. R. Liu, B. Hu, Q. Liu, Y. Sun, and Y. S. Wang, "Source apportionment of urban fine particle number concentration during summertime in Beijing," Atmos. Environ., vol. 96, pp. 359-369, Oct. 2014.

[19] F. Salimi et al., "Assessment and application of clustering techniques to atmospheric particle number size distribution for the purpose of source apportionment," Atmos Chem Phys, vol. 14, no. 21, pp. 11883-11892, Nov. 2014.

[20] J. J. Schauer, W. F. Rogge, L. M. Hildemann, M. A. Mazurek, G. R. Cass, and B. R. T. Simoneit, "Source apportionment of airborne particulate matter using organic compounds as tracers," Atmos. Environ., vol. 30, no. 22, pp. 3837-3855, Nov. 1996.

[21] J. P. Shi, A. A. Khan, and R. M. Harrison, "Measurements of ultrafine particle concentration and size distribution in the urban atmosphere," Sci. Total Environ., vol. 235, no. 1-3, pp. 51-64, Sep. 1999.

[22] G. R. Cass, L. A. Hughes, P. Bhave, M. J. Kleeman, J. O. Allen, and L. G. Salmon, "The chemical composition of atmospheric ultrafine particles," Philos. Trans. R. Soc. Lond. Math. Phys. Eng. Sci., vol. 358, no. 1775, pp. 2581-2592, Oct. 2000.

[23] R. M. Harrison et al., "Measurement of number, mass and size distribution of particles in the atmosphere," Philos. Trans. R. Soc. Lond. Math. Phys. Eng. Sci., vol. 358, no. 1775, pp. 2567-2580, Oct. 2000.

[24] J. Hitchins, L. Morawska, R. Wolff, and D. Gilbert, "Concentrations of submicrometre particles from vehicle emissions near a major road," Atmos. Environ., vol. 34, no. 1, pp. 51-59, Jan. 2000.

[25] P. M. Fine, S. Shen, and C. Sioutas, "Inferring the Sources of Fine and Ultrafine Particulate Matter at Downwind Receptor Sites in the Los Angeles Basin Using Multiple Continuous Measurements Special Issue of Aerosol Science and Technology on Findings from the Fine Particulate Matter Supersites Program," Aerosol Sci. Technol., vol. 38, no. sup1, pp. 182-195, Dec. 2004. 
[26] K. M. Zhang, A. S. Wexler, Y. F. Zhu, W. C. Hinds, and C. Sioutas, "Evolution of particle number distribution near roadways. Part II: the 'Road-to-Ambient' process," Atmos. Environ., vol. 38, no. 38, pp. 6655-6665, Dec. 2004.

[27] "2001 Annual Report | Characterization of the Chemical Composition of Atmospheric Ultrafine Particles| Research Project Database | NCER | ORD | US EPA."

[28] J. Pey, X. Querol, A. Alastuey, S. Rodríguez, J. P. Putaud, and R. Van Dingenen, "Source apportionment of urban fine and ultra-fine particle number concentration in a Western Mediterranean city," Atmos. Environ., vol. 43, no. 29, pp. 4407-4415, Sep. 2009.

[29] P. Kumar, A. Robins, S. Vardoulakis, and R. Britter, "A review of the characteristics of nanoparticles in the urban atmosphere and the prospects for developing regulatory controls," Atmos. Environ., vol. 44, no. 39, pp. 5035-5052, Dec. 2010.

[30] M. Ketzel et al., "Particle size distribution and particle mass measurements at urban,near-city and rural level in the Copenhagen area and Southern Sweden," Atmos Chem Phys, vol. 4, no. 1, pp. 281-292, Feb. 2004.

[31] T. M. Tuch et al., "Weak correlation of ultrafine aerosol particle concentrations $<800 \mathrm{~nm}$ between two sites within one city," J. Expo. Sci. Environ. Epidemiol., vol. 16, no. 6, pp. 486-490, Jan. 2006.

[32] M. A. Pohjola et al., "Evaluation and modelling of the size fractionated aerosol particle number concentration measurements nearby a major road in Helsinki - Part I: Modelling results within the LIPIKA project," Atmos Chem Phys, vol. 7, no. 15, pp. 4065-4080, Aug. 2007.

[33] Y. Wang, P. K. Hopke, D. C. Chalupa, and M. J. Utell, "Long-term study of urban ultrafine particles and other pollutants," Atmos. Environ., vol. 45, no. 40, pp. 76727680, Dec. 2011. 
[34] M. J. Kleeman, J. J. Schauer, and G. R. Cass, "Size and Composition Distribution of Fine Particulate Matter Emitted from Motor Vehicles," Environ. Sci. Technol., vol. 34, no. 7, pp. 1132-1142, Apr. 2000.

[35] M. A. Robert, S. VanBergen, M. J. Kleeman, and C. A. Jakober, "Size and Composition Distributions of Particulate Matter Emissions: Part 1-Light-Duty Gasoline Vehicles," J. Air Waste Manag. Assoc., vol. 57, no. 12, pp. 1414-1428, Dec. 2007.

[36] M. A. Robert, M. J. Kleeman, and C. A. Jakober, "Size and Composition Distributions of Particulate Matter Emissions: Part 2-Heavy-Duty Diesel Vehicles," J. Air Waste Manag. Assoc., vol. 57, no. 12, pp. 1429-1438, Dec. 2007.

[37] S. Janhäll, Å. M. Jonsson, P. Molnár, E. A. Svensson, and M. Hallquist, "Size resolved traffic emission factors of submicrometer particles," Atmos. Environ., vol. 38, no. 26, pp. 4331-4340, Aug. 2004.

[38] D. B. Kittelson, W. F. Watts, and J. P. Johnson, "Nanoparticle emissions on Minnesota highways," Atmos. Environ., vol. 38, no. 1, pp. 9-19, Jan. 2004.

[39] P. Molnár, S. Janhäll, and M. Hallquist, "Roadside measurements of fine and ultrafine particles at a major road north of Gothenburg," Atmos. Environ., vol. 36, no. 25, pp. 4115-4123, Sep. 2002.

[40] D. B. Kittelson, "Engines and nanoparticles: a review," J. Aerosol Sci., vol. 29, no. 5-6, pp. 575-588, Jun. 1998.

[41] S. J. Harris and M. M. Maricq, "Signature size distributions for diesel and gasoline engine exhaust particulate matter," J. Aerosol Sci., vol. 32, no. 6, pp. 749-764, Jun. 2001.

[42] Z. D. Ristovski, E. R. Jayaratne, M. Lim, G. A. Ayoko, and L. Morawska, "Influence of Diesel Fuel Sulfur on Nanoparticle Emissions from City Buses," Environ. Sci. Technol., vol. 40, no. 4, pp. 1314-1320, Feb. 2006. 
[43] T. W. Kirchstetter, R. A. Harley, N. M. Kreisberg, M. R. Stolzenburg, and S. V. Hering, "On-road measurement of fine particle and nitrogen oxide emissions from light- and heavy-duty motor vehicles," Atmos. Environ., vol. 33, no. 18, pp. 29552968, Aug. 1999.

[44] “Microsoft PowerPoint - 5-Matti Maricq.ppt - session6_5_mattimaricq.pdf."

[45] P. Wahlina, F. Palmgren, and R. Van Dingenen, "Experimental studies of ultrafine particles in streets and the relationship to traffic," Atmos. Environ., vol. 35, pp. S63S69, Jan. 2001.

[46] V. V. Karasev et al., "Formation of charged soot aggregates by combustion and pyrolysis: charge distribution and photophoresis," J. Aerosol Sci., vol. 35, no. 3, pp. 363-381, Mar. 2004.

[47] J. M. Ondov and A. S. Wexler, "Where Do Particulate Toxins Reside? An Improved Paradigm for the Structure and Dynamics of the Urban Mid-Atlantic Aerosol," Environ. Sci. Technol., vol. 32, no. 17, pp. 2547-2555, Sep. 1998.

[48] R. M. Harrison, M. Jones, and G. Collins, "Measurements of the physical properties of particles in the urban atmosphere," Atmos. Environ., vol. 33, no. 2, pp. 309-321, Jan. 1999.

[49] A. Charron and R. M. Harrison, "Primary particle formation from vehicle emissions during exhaust dilution in the roadside atmosphere," Atmos. Environ., vol. 37, no. 29, pp. 4109-4119, Sep. 2003.

[50] P. J. Sturm et al., "Roadside measurements of particulate matter size distribution," Atmos. Environ., vol. 37, no. 37, pp. 5273-5281, Dec. 2003.

[51] G. Gramotnev and Z. Ristovski, "Experimental investigation of ultra-fine particle size distribution near a busy road," Atmos. Environ., vol. 38, no. 12, pp. 1767-1776, Apr. 2004. 
[52] E. Rosenbohm et al., "Particulate size distributions and mass measured at a motorway during the BAB II campaign," Atmos. Environ., vol. 39, no. 31, pp. 56965709, Oct. 2005.

[53] D. Westerdahl, S. Fruin, T. Sax, P. M. Fine, and C. Sioutas, "Mobile platform measurements of ultrafine particles and associated pollutant concentrations on freeways and residential streets in Los Angeles," Atmos. Environ., vol. 39, no. 20, pp. 3597-3610, Jun. 2005.

[54] L. Ntziachristos, Z. Ning, M. D. Geller, and C. Sioutas, "Particle Concentration and Characteristics near a Major Freeway with Heavy-Duty Diesel Traffic," Environ. Sci. Technol., vol. 41, no. 7, pp. 2223-2230, Apr. 2007.

[55] M. Pitz, W. G. Kreyling, B. Hölscher, J. Cyrys, H. E. Wichmann, and J. Heinrich, "Change of the ambient particle size distribution in East Germany between 1993 and 1999," Atmos. Environ., vol. 35, no. 25, pp. 4357-4366, Sep. 2001.

[56] M. Ketzel, P. Wåhlin, R. Berkowicz, and F. Palmgren, "Particle and trace gas emission factors under urban driving conditions in Copenhagen based on street and roof-level observations," Atmos. Environ., vol. 37, no. 20, pp. 2735-2749, Jun. 2003.

[57] M. Kulmala et al., "Formation and growth rates of ultrafine atmospheric particles: a review of observations," J. Aerosol Sci., vol. 35, no. 2, pp. 143-176, Mar. 2004.

[58] T. Rönkkö, A. Virtanen, K. Vaaraslahti, J. Keskinen, L. Pirjola, and M. Lappi, “Effect of dilution conditions and driving parameters on nucleation mode particles in diesel exhaust: Laboratory and on-road study," Atmos. Environ., vol. 40, no. 16, pp. 28932901, May 2006.

[59] A. Alam, J. P. Shi, and R. M. Harrison, "Observations of new particle formation in urban air," J. Geophys. Res. Atmospheres, vol. 108, no. D3, p. 4093, Feb. 2003.

[60] K. Sabaliauskas and G. Evans, "Exposure to Ultrafine Particles in Urban Centres," in Urban Airborne Particulate Matter, F. Zereini and C. L. S. Wiseman, Eds. Springer Berlin Heidelberg, 2010, pp. 483-499. 
[61] Zhang, K. M., Wexler, A. S., Zhu, Y. F., Hinds, W. C., \& Sioutas, C, "Evolution of particle number distribution near roadways. Part II: the "Road-to Ambient process." Atmospheric Environ. ,vol. 38, no. 38, 2004.

[62] Y. Zhu, W. C. Hinds, S. Kim, S. Shen, and C. Sioutas, "Study of ultrafine particles near a major highway with heavy-duty diesel traffic," Atmos. Environ., vol. 36, no. 27, pp. 4323-4335, Sep. 2002.

[63] D. Brugge, J. L. Durant, and C. Rioux, "Near-highway pollutants in motor vehicle exhaust: A review of epidemiologic evidence of cardiac and pulmonary health risks," Environ. Health, vol. 6, p. 23, Aug. 2007.

[64] G. Hoek et al., "Concentration Response Functions for Ultrafine Particles and AllCause Mortality and Hospital Admissions: Results of a European Expert Panel Elicitation," Environ. Sci. Technol., vol. 44, no. 1, pp. 476-482, Jan. 2010.

[65] T. S. Nawrot et al., "Stronger associations between daily mortality and fine particulate air pollution in summer than in winter: evidence from a heavily polluted region in western Europe," J. Epidemiol. Community Health, vol. 61, no. 2, pp. 146149, Feb. 2007.

[66] W. He et al., "Daily mortality and fine and ultrafine particles in Erfurt, Germany part I: role of particle number and particle mass.," Res. Rep. Health Eff. Inst., no. 98, pp. 5-86-94, 20002000.

[67] A. Peters, H. E. Wichmann, T. Tuch, J. Heinrich, and J. Heyder, "Respiratory effects are associated with the number of ultrafine particles.," Am. J. Respir. Crit. Care Med., vol. 155, no. 4, pp. 1376-1383, Apr. 1997.

[68] A. Peters, A. Döring, H. E. Wichmann, and W. Koenig, "Increased plasma viscosity during an air pollution episode: a link to mortality?," Lancet Lond. Engl., vol. 349, no. 9065, pp. 1582-1587, May 1997. 
[69] P. Penttinen, K. L. Timonen, P. Tiittanen, A. Mirme, J. Ruuskanen, and J. Pekkanen, "Ultrafine particles in urban air and respiratory health among adult asthmatics," Eur. Respir. J., vol. 17, no. 3, pp. 428-435, Mar. 2001.

[70] S. von Klot et al., "Increased asthma medication use in association with ambient fine and ultrafine particles," Eur. Respir. J., vol. 20, no. 3, pp. 691-702, Sep. 2002.

[71] J. Pekkanen et al., "Particulate Air Pollution and Risk of ST-Segment Depression During Repeated Submaximal Exercise Tests Among Subjects With Coronary Heart Disease," Circulation, vol. 106, no. 8, pp. 933-938, Aug. 2002.

[72] J. J. de Hartog et al., "Effects of Fine and Ultrafine Particles on Cardiorespiratory Symptoms in Elderly Subjects with Coronary Heart Disease The ULTRA Study," Am. J. Epidemiol., vol. 157, no. 7, pp. 613-623, Apr. 2003.

[73] "Human respiratory tract model for radiological protection. A report of a Task Group of the International Commission on Radiological Protection," Ann. ICRP, vol. 24, no. 1-3, pp. 1-482, 1994.

[74] A. Nemmar et al., "Passage of Inhaled Particles Into the Blood Circulation in Humans," Circulation, vol. 105, no. 4, pp. 411-414, Jan. 2002.

[75] G. Oberdörster et al., "Extrapulmonary Translocation of Ultrafine Carbon Particles Following Whole-Body Inhalation Exposure of Rats," J. Toxicol. Environ. Health A, vol. 65, no. 20, pp. 1531-1543, Oct. 2002.

[76] W. G. Kreyling, M. Semmler, and W. Möller, "Dosimetry and Toxicology of Ultrafine Particles," J. Aerosol Med., vol. 17, no. 2, pp. 140-152, Jun. 2004.

[77] N. Li et al., "Ultrafine particulate pollutants induce oxidative stress and mitochondrial damage," Environ. Health Perspect., vol. 111, no. 4, pp. 455-460, Apr. 2003.

[78] V. Stone et al., "Increased calcium influx in a monocytic cell line on exposure to ultrafine carbon black," Eur. Respir. J., vol. 15, no. 2, pp. 297-303, Feb. 2000. 
[79] K. Donaldson, V. Stone, A. Clouter, L. Renwick, and W. MacNee, "Ultrafine particles," Occup. Environ. Med., vol. 58, no. 3, pp. 211-216, 199, Mar. 2001.

[80] K. Donaldson et al., "The pulmonary toxicology of ultrafine particles," J. Aerosol Med. Off. J. Int. Soc. Aerosols Med., vol. 15, no. 2, pp. 213-220, 2002.

[81] D. C. Chalupa, P. E. Morrow, G. Oberdörster, M. J. Utell, and M. W. Frampton, "Ultrafine particle deposition in subjects with asthma.," Environ. Health Perspect., vol. 112, no. 8, pp. 879-882, Jun. 2004.

[82] C. M. Kendrick, "Improving the Roadside Environment through Integrating Air Quality and Traffic-Related Data," Portland State University, 2016.

[83] C. M. Kendrick, D. Urowsky, W. Rotich, P. Koonce, and L. A. George, "Effect of Reducing Maximum Cycle Length on Roadside Air Quality and Travel Times on a Corridor in Portland, OR," 2014.

[84] Ang-Olson, J., \& Ostria, S.,"Assessing the effects of freight movement on air quality at the national and regional level." Office of Natural and Human Environment, US Federal Highway Administration, Washington, DC. 2005

[85] K. O. K. Oduyemi and B. Davidson, "The impacts of road traffic management on urban air quality1," Sci. Total Environ., vol. 218, no. 1, pp. 59-66, Jul. 1998.

[86] D. Carr et al., "Modeling Annual Benzene, Toluene, NO2, and Soot Concentrations on the Basis of Road Traffic Characteristics," Environ. Res., vol. 90, no. 2, pp. 111-118, Oct. 2002.

[87] M. Grundström, C. Hak, D. Chen, M. Hallquist, and H. Pleijel, "Variation and covariation of PM10, particle number concentration, NOx and NO2 in the urban air Relationships with wind speed, vertical temperature gradient and weather type," Atmos. Environ., vol. 120, pp. 317-327, Nov. 2015. 
[88] "Measurement of Atlanta Aerosol Size Distributions: Observations of Ultrafine Particle Events - 02786820120056.".

[89] B. Wehner, W. Birmili, T. Gnauk, and A. Wiedensohler, "Particle number size distributions in a street canyon and their transformation into the urban-air background: measurements and a simple model study," Atmos. Environ., vol. 36, no. 13, pp. 2215-2223, May 2002.

[89]P. Molnár, S. Janhäll, and M. Hallquist, "Roadside measurements of fine and ultrafine particles at a major road north of Gothenburg," Atmos. Environ., vol. 36, no. 25, pp. 4115-4123, Sep. 2002.

[91] L. Gidhagen, C. Johansson, J. Langner, and G. Olivares, "Simulation of NOx and ultrafine particles in a street canyon in Stockholm, Sweden," Atmos. Environ., vol. 38, no. 14, pp. 2029-2044, May 2004.

[92] J. P. Shi, D. E. Evans, A. A. Khan, and R. M. Harrison, "Sources and concentration of nanoparticles (<10 nm diameter) in the urban atmosphere," Atmos. Environ., vol. 35, pp. 1193-1202, 2001.

[93] M. Pohjola, L. Pirjola, J. Kukkonen, and M. Kulmala, "Modelling of the influence of aerosol processes for the dispersion of vehicular exhaust plumes in street environment," Atmos. Environ., vol. 37, no. 3, pp. 339-351, Jan. 2003.

[94] D. C. Carslaw and S. D. Beevers, "Estimations of road vehicle primary NO2 exhaust emission fractions using monitoring data in London," Atmos. Environ., vol. 39, no. 1, pp. 167-177, Jan. 2005.

[95] M. G. Snyder, A. Venkatram, D. K. Heist, S. G. Perry, W. B. Petersen, and V. Isakov, "RLINE: A line source dispersion model for near-surface releases," Atmos. Environ., vol. 77, pp. 748-756, Oct. 2013.

[96] A. J. Cimorelli et al., "AERMOD: A Dispersion Model for Industrial Source Applications. Part I: General Model Formulation and Boundary Layer Characterization," J. Appl. Meteorol., vol. 44, no. 5, pp. 682-693, May 2005. 
[97] T. W. Kirchstetter, R. A. Harley, N. M. Kreisberg, M. R. Stolzenburg, and S. V. Hering, "On-road measurement of fine particle and nitrogen oxide emissions from light- and heavy-duty motor vehicles," Atmos. Environ., vol. 33, no. 18, pp. 29552968, Aug. 1999.

[98] C. A. Noble et al., "Continuous measurement of fine and ultrafine particulate matter, criteria pollutants and meteorological conditions in urban El Paso, Texas," Atmos. Environ., vol. 37, no. 6, pp. 827-840, Feb. 2003.

[99] D. B. Kittelson, W. F. Watts, and J. P. Johnson, "Nanoparticle emissions on Minnesota highways," Atmos. Environ., vol. 38, no. 1, pp. 9-19, Jan. 2004.

[100] S. JanhÄll and M. Hallquist, "A Novel Method for Determination of Size-Resolved, Submicrometer Particle Traffic Emission Factors," Environ. Sci. Technol., vol. 39, no. 19, pp. 7609-7615, Oct. 2005.

[101] M. Jamriska and L. Morawska, "A model for determination of motor vehicle emission factors from on-road measurements with a focus on submicrometer particles," Sci. Total Environ., vol. 264, no. 3, pp. 241-255, Jan. 2001.

[102] G. Gramotnev, R. Brown, Z. Ristovski, J. Hitchins, and L. Morawska, "Determination of average emission factors for vehicles on a busy road," Atmos. Environ., vol. 37, no. 4, pp. 465-474, Feb. 2003.

[103] B. R. Graskow, D. B. Kittelson, I. S. Abdul-Khalek, M. R. Ahmadi, and J. E. Morris, "Characterization of Exhaust Particulate Emissions from a Spark Ignition Engine," 1998.

[104] “Microsoft Word - Gasoline particulate report_final.docx - rpt_16-10.pdf."

[105] D. J. Rickeard, J. R. Bateman, Y. K. Kwon, J. J. McAughey, and C. J. Dickens, "Exhaust Particulate Size Distribution: Vehicle and Fuel Influences in Light Duty Vehicles," 1996. 
[106] Z. D. Ristovski, E. R. Jayaratne, M. Lim, G. A. Ayoko, and L. Morawska, "Influence of Diesel Fuel Sulfur on Nanoparticle Emissions from City Buses," Environ. Sci. Technol., vol. 40, no. 4, pp. 1314-1320, Feb. 2006.

[107] J. Farnlund, C. Holman, and P. Kageson, "EMISSIONS OF ULTRAFINE PARTICLES FROM DIFFERENT TYPES OF LIGHT DUTY VEHICLES,” Jan. 2001.

[108] L. Morawska, N. D. Bofinger, L. Kocis, and A. Nwankwoala, "Submicrometer and Supermicrometer Particles from Diesel Vehicle Emissions," Environ. Sci. Technol., vol. 32, no. 14, pp. 2033-2042, Jul. 1998.

[109] R. N. Colvile, E. J. Hutchinson, J. S. Mindell, and R. F. Warren, "The transport sector as a source of air pollution," Atmos. Environ., vol. 35, no. 9, pp. 1537-1565, Mar. 2001.

[110] S. J. Harris and M. M. Maricq, "Signature size distributions for diesel and gasoline engine exhaust particulate matter," J. Aerosol Sci., vol. 32, no. 6, pp. 749-764, Jun. 2001.

[111] B. Zielinska, J. Sagebiel, J. D. McDonald, K. Whitney, and D. R. Lawson, "Emission rates and comparative chemical composition from selected in-use diesel and gasoline-fueled vehicles," J. Air Waste Manag. Assoc. 1995, vol. 54, no. 9, pp. 11381150, Sep. 2004.

[112] N. R. Council, Rethinking the Ozone Problem in Urban and Regional Air Pollution. 1992. 